NBER WORKING PAPER SERIES

\title{
ACCOUNTING FOR INNOVATION IN CONSUMER DIGITAL SERVICES: IT STILL MATTERS
}

\author{
David Byrne \\ Carol Corrado \\ Working Paper 26010 \\ http://www.nber.org/papers/w26010 \\ NATIONAL BUREAU OF ECONOMIC RESEARCH \\ 1050 Massachusetts Avenue \\ Cambridge, MA 02138 \\ June 2019, Revised February 2020
}

The views expressed in this paper are those of the authors and do not necessarily reflect those of the Board of Governors, other members of its staff, or the National Bureau of Economic Research. Corresponding author (cac289@georgetown.edu) This paper was prepared for the NBER/CRIW Conference, "Measuring Innovation in the 21st Century," Georgetown University, Washington, D.C., March 10-11, 2017. We have benefited from presentations of this paper at the 5th IMF Statistical Forum in Washington, D.C.(November 2017), the ESCoE Measurement Conference in London (May 2018) and the 5th World KLEMS Conference in Cambridge, Mass (June 2018). We received no financial support for this paper.

NBER working papers are circulated for discussion and comment purposes. They have not been peer-reviewed or been subject to the review by the NBER Board of Directors that accompanies official NBER publications.

(C) 2019 by David Byrne and Carol Corrado. All rights reserved. Short sections of text, not to exceed two paragraphs, may be quoted without explicit permission provided that full credit, including $(\odot$ notice, is given to the source. 
Accounting for Innovation in Consumer Digital Services: IT Still Matters

David Byrne and Carol Corrado

NBER Working Paper No. 26010

June 2019, Revised February 2020

JEL No. E01,E21,E22,O31

\begin{abstract}
$\underline{\text { ABSTRACT }}$
This paper develops a framework for measuring digital services in the face of ongoing innovations in the delivery of content to consumers. We capture what Brynjolfsson and Saunders (2009) call "free goods" as the capital services generated by connected consumers' stocks of IT digital goods, a service flow that augments the existing measure of personal consumption in GDP. Its value is determined by the intensity with which households use their IT capital to consume content delivered over networks, and its volume depends on the quality of the IT capital. Consumers pay for delivery services, however, and the complementarity between device use and network use enables us to develop a quality-adjusted price measure for the access services already included in GDP.

Our new estimates imply that accounting for innovations in consumer content delivery matters: The innovations boost consumer surplus by nearly $\$ 2,000$ (2017 dollars) per connected user per year for the full period of this study (1987 to 2017) and contribute .6 percentage point per year to US real GDP growth during the last ten. All told, our more complete accounting of innovations is (conservatively) estimated to have moderated the post-2007 GDP growth slowdown by .3 percentage points per year.
\end{abstract}

\author{
David Byrne \\ Federal Reserve Board \\ 20th \& Constitution Ave., NW \\ Washington, DC 20551 \\ david.m.byrne@frb.gov \\ Carol Corrado \\ The Conference Board \\ 845 Third Avenue \\ New York, NY 10022-6679 \\ Carol.Corrado@conference-board.org
}




\section{Introduction}

Capturing the impact of innovations in consumer content delivery in conventional well-being measures, e.g., GDP, presents significant challenges. It also seemingly requires a new approach because the manifestation of these innovations in consumer welfare (e.g., time spent consuming high quality content via networked IT devices) does not involve a market transaction at the time of consumption, which is where price collectors/estimators look to pick up new goods as they appear. Figure 1 shows that innovations in consumer content delivery have been very rapid since the turn of this century, suggesting their impacts may be missed in existing GDP; indeed, they are clustered in the mid-2000's when the slow down in the trend GDP growth emerged. Is it possible that the substitution of uncounted, so-called free goods for purchased counterparts is a culprit in this much-discussed slowdown?

This paper adapts a not-so-new approach - capitalization of consumer digital goods - to address this question, but the standard approach is augmented with an accounting for how IT devices and subscription network access services are used and consumed 1 To understand why a use-adjusted version of an "old" approach is both (a) needed and (b) up to the task of capturing 21st century innovations, consider first that it is consumer-owned devices with advanced processing technologycomputers, powerful smartphones, smart TVs, and video game consoles - that enable the consumption of high quality content in many homes (and elsewhere), and these services currently are uncounted in national accounts (though their paid-for predecessors often were). Consider next that the spread of broadband since 2000 and rise of social media since 2004 suggests that the use of services that enable the delivery of content to consumer has risen dramatically (see figure 2). The rise in use of network services implies greater consumption volume (for a given number of subscriptions) because subscription costs do not fully depend on use rates. All told, we translate the problem of capturing the innovations shown in figure 1 -including what Brynjolfsson and Saunders (2009) call "free goods" - into a quest for comprehensive measurement of (a) consumer services derived from IT device use and (b) consumer network service volumes in constant-quality terms. (a) involves an imputation to GDP for the missing services and (b) involves creating a new price index for the paid-for services.

Because consumers' IT capital use is inextricably tied to households' utilization of public broadband, wireless, and cable networks (including their take up of over-the-top (OTT) media and personal

\footnotetext{
${ }^{1}$ The standard approach refers to the productivity literature that capitalizes consumer durables, originally due to Christensen and Jorgenson (1969, 1973); see also Jorgenson and Landefeld (2006). The U.S. national accounts do not capitalize consumer durables in headline GDP.
} 
Figure 1: Timeline of Innovations in Consumer Content Delivery

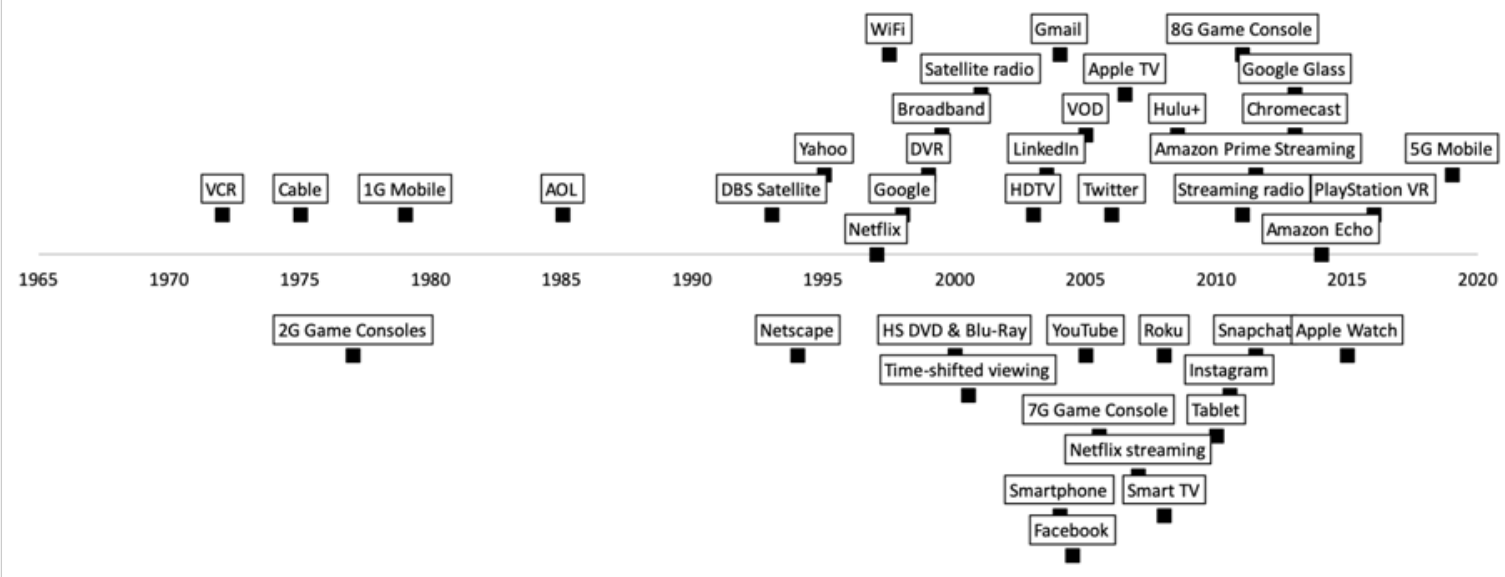

Source: Authors' adaption and extension of information in Total Audience Report, The Neilsen Company, December 3, 2014, available at http://www.nielsen.com/us/en/insights/reports/2014/the-total-audience-report.html.

cloud services), its imputation must be linked to paid-for services. In other words, home services and paid-for services exhibit demand complementarity $\left.\right|^{2}$, and a joint analysis of these two types of consumer digital services is required. This aspect of the approach to capitalization of consumer digital capital is novel with this paper. A related literature addresses the measurement of "free goods" using alternative methods and very different frameworks (Nakamura, Samuels, and Soloveichik, 2016; Nakamura, Soloveichik, and Samuels, 2018, Brynjolfsson, Collis, and Eggers, 2019; Brynjolfsson, Collis, Diewert, Eggers, and Fox, 2019); we compare our findings to these works later in this paper.

\section{Figure 2: Consumer Digital Capital Use}

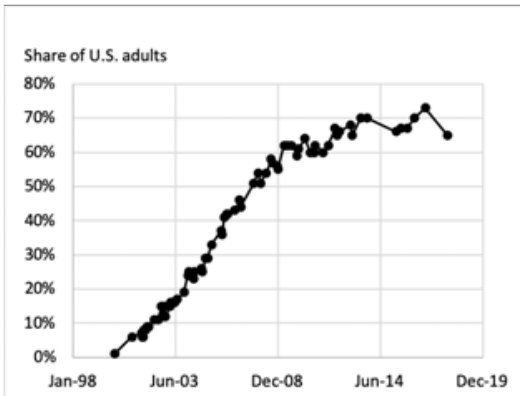

(a) Broadband Use

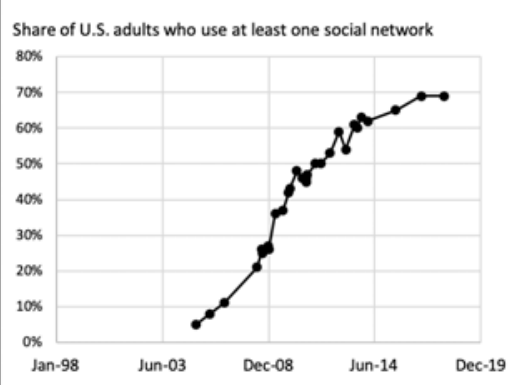

(b) Social Media Use

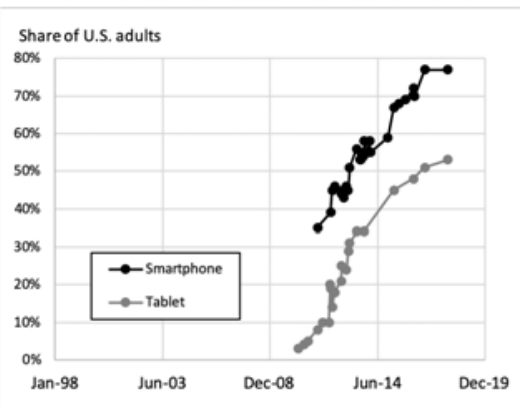

(c) Mobile Device Use

SOURCE: Pew Center for the Internet

\footnotetext{
${ }^{2}$ Thanks to Shane Greenstein for suggesting this interpretation.
} 
The roadmap of this paper is as follows. Section 2 sets out our framework for thinking about how the standard framework for capitalizing consumer digital goods needs to be adjusted to take into account the dramatic increase in household digital asset use shown in figure 2. Then we review the relationship between device use rates and the volume of services that deliver content over networks, which forms the basis for the quality-adjusted price index for network access services developed in this paper. Section 4 summarizes our empirical findings in terms of impacts on real GDP and consumer surplus. Section 5 concludes.

Our new estimates imply that accounting for innovations in consumer content delivery matters: The innovations boost consumer surplus by nearly $\$ 1,920$ (2017 dollars) per connected user per year for the full period of this study (1987 to 2017) and contribute .6 percentage point to US real GDP growth during the last ten (2007 to 2017). All told, our more complete accounting of innovations is (conservatively) estimated to have moderated the post-2007 US real GDP growth slowdown by .3 percentage point per year. Because some of this GDP kick comes from an imputation (akin to the imputation for services from owner-occupied housing), the measured slowdown in business productivity growth is shaved by somewhat less, about .2 percentage point per year.

\section{Framework: Demand Complementarity}

Digital device services and network access services work together to deliver consumer content. This section illustrates how their demand complementarity can be exploited to capture and account for quality change in consumer digital services.

\subsection{Definitions}

Because consumer digital services reflect both households' use of digital devices and households' take

up of network access services, the value of total consumer digital (T) services, $P^{S_{T}} S_{T}$, is expressed as the sum of two components:

$$
P^{S_{T}} S_{T}=P^{S_{T}^{H}} S_{T}^{H}+P^{S_{T}^{B}} S_{T}^{B}
$$

The components are nonmarket (or "home") and market (or "paid-for") services, respectively, where superscripts on the component digital services volume indexes (the $S$ 's) denote location of the capital used to deliver each type service, i.e., business sector $(B)$ or household sector $(H)$. 
Home services, $P^{S_{T}^{H}} S_{T}^{H}$, are generated via households' use of IT goods purposed for accessing digital networks $3^{3}$ Paid-for services, $P^{S_{T}^{B}} S_{T}^{B}$, are derived from subscriptions to networks, e.g., payments for internet access, cellular access, etc. Where are the seemingly "free" services provided by Google, Facebook and other apps? Our answer is that they are embodied in both nonmarket and market services in this framework. The demand for consumer IT capital is a derived demand induced by the availability of search engines, social networks (and so forth) that push users to purchase higher quality equipment for, e.g., streaming YouTube and Netflix videos. The intensity of use of network access services is increased because the "free" services require that data-pictures, videos, search resultsneed to be delivered from the cloud for configuration and display by browsers and/or apps on the home device. It is tempting to associate the capture of "free goods" as solved by the imputation for home services that we propose in this paper, but the derived demand dynamic underscores it is equally important to use quality-adjusted price statistics for the purchased parts of content delivery systems, as improvements in quality are also seemingly "free."

Quality change is reflected in the price indexes of both components of (1). It stems from (a) the quality of the equipment used to access content via networks (e.g., the storage capacity of smartphones, etc.), (b) the quality of network services (e.g., download and upload speeds of broadband service, channel variety in video service, etc.), and (c) the use intensity of the combined content delivery system (i.e., the equipment plus the access service). After controlling for the quality of systems (equipment cum access services) at the time of their purchase, the change in system use intensity reflects changes in the system's performance, i.e., change in the marginal product of its combined net capital stocks (just as ex post private capital income reflects changes in the return to capital). Not much of (b) and none of (c) is in existing GDP, and while (a) is included to a significant degree, we improve its capture in this paper.

Network use intensity reflects how consumers use their IT devices and is revealed by the take up of paid-for network access services. Denoting network use intensity by $\lambda$, and letting $N$ be the number of users on the network (i.e., consumer accounts, from the perspective of the service provider), then average network use intensity is defined as:

$$
\lambda=\frac{S_{T}^{B}}{N}
$$

\footnotetext{
${ }^{3}$ IT goods used without network access produce uncounted services as well, such as personal computer used to work on local files. This use is outside the scope of our analysis.
} 
where $S_{T}^{B}$ is the volume of paid-for access services consumed, per equation (1). $\lambda$ and $N$ are most easily understood from a producer perspective, i.e., $\lambda$ is an intensive per customer use margin and $N$ is an extensive margin whose increases reflect customer growth, e.g., for broadband providers, the number of "customers" $N$ is households with broadband subscriptions. For cellular service providers, $N$ is individuals with cellular phone subscriptions..$^{4}$

There are other, largely demographically-driven, dimensions of use, e.g., the number of users per household and the age of users, as this feeds into hours of use per connection. Note that per equation (2) these distinctions in margins of use are implicit in $\lambda$ to the extent they are not counted in $N$.

\subsection{Home services}

Our starting point is the Christensen and Jorgenson (1969, 1973) framework, based on Jorgenson (1963), for imputing service flows from capitalized consumer durables. Letting $K_{T}^{H}$ denote the net stock of digital goods held by consumers and $P^{K_{T}^{H}}$ the per period rental price for use of a unit of those stocks, then the value of their capital services $P^{K_{T}^{H}} K_{T}^{H}$ in the standard formulation would be given by:

$$
P^{K_{T}^{H}} K_{T}^{H}=\left(\bar{\rho}+\delta_{T}^{H}\right) P^{I_{T}^{H}} K_{T}^{H}
$$

where $\bar{\rho}$ is an ex ante real household discount rate, $\delta_{T}^{H}$ is a depreciation rate for household IT stocks, and $P^{I_{T}^{H}}$ is a quality-adjusted asset price index for new investments in those stocks.

Nominal home services for consumer digital goods, the $P^{S_{T}^{H}} S_{T}^{H}$ term in equation (1), does not correspond to equation (3) because (3) is essentially a capacity flow; i.e., (3) does not reflect actual consumption $\sqrt[5]{5}$ Demand complementarity suggests that incorporating the "connected" IT use dynamic implied by figure 2 is necessary to capture the actual consumption of digital content over networks in $P^{S_{T}^{H}} S_{T}^{H}$

The IT device use dynamic is specific to each device type, which implies we need to define a use rate $\psi_{a}$ for each asset type $a$, e.g., for computers, for mobile phones, for TVs, etc. We thus have the

\footnotetext{
${ }^{4}$ Although households have other modes of network service (e.g., cable, OTT) and all such services are considered in our empirical analysis, for simplicity, the discussion in this section considers $N$ as the number of subscriptions to a single service, i.e., connected households.

${ }^{5}$ Private industry capital income is generally understood to include a utilization effect when the rate of return is calculated on an ex post basis as in Jorgenson and Griliches (1967). When consumer durables are capitalized, service flows are imputed using an ex ante return as in (3), and therefore a utilization effect is not be "automatically" present. See Hulten (2009) for a discussion.
} 
following

$$
\psi_{a}=\left(\frac{D e v_{a}}{D^{*}}\right)
$$

where $D e v_{a}$ is the number of hours per day device type $a$ is used to connect to networks, and $D^{*}$ is the potential number of hours per day any device can be used.

We can then define an "effective" stock of network access equipment and software, $K_{T}^{e H}$, that accounts for how the use of a given stock of network access equipment and software expands, in which case the value of nonmarket consumer digital services in equation (1) is given by:

$$
\begin{aligned}
P^{S_{T}^{H}} S_{T}^{H} & =P^{K_{T}^{H}} K_{T}^{e H} \\
& =\psi \cdot P^{K_{T}^{H}} K_{T}^{H} .
\end{aligned}
$$

where $\psi$ reflects the appropriately weighted aggregate of the individual $\psi_{a}$ 's. A related issue is that some consumer digital capital goods are not used for the consumption of content over networks, e.g., digital cameras, suggesting it is necessary to identify a relevant group of IT devices - call this network access equipment (NAE) - for generating the relevant capital services flows. The relevant IT products comprising NAE stocks will be identified in measurement; we thus proceed with the assumption that only NAE products are included in the capital measures subscripted by " $T$ ".

Consider next how to measure the implicit volume of services whose value is given by $5 \mathrm{~b}$, $\log$ differentiation of equations $(5 \mathrm{~b})$ and (3), holding $\bar{\rho}$ and $\delta_{T}^{H}$ constant, suggests that the growth of nominal free services $\dot{P}^{H}+\dot{S}_{T}^{H}$ is equal to $P^{\dot{K}_{T}^{H}}+\dot{K}_{T}^{e}$. This in turn implies that $P^{\dot{S}_{T}^{H}}=P^{I_{T}^{H}}$, and that growth of real services $\dot{S}_{T}^{H}$ equals the growth of the effective stock $\dot{K}_{T}^{\dot{e}}$, or

$$
\begin{aligned}
\dot{S}_{T}^{H} & =\dot{K^{e}}{ }_{T}^{H} \\
& =\dot{K}_{T}^{H}+\dot{\psi} .
\end{aligned}
$$

\subsection{Paid-for services}

Digital access services are typically sold as subscriptions, where households pay a monthly fee for a "plan" in return for access to a range of services, e.g., broadband, smartphone, cable TV, subscription 
video-on-demand. Each plan has a fixed set of characteristics, e.g., download speed, upload speed, number/availability of videos or video channels, etc., for the services involved. Plan heterogeneity by service type and service type characteristics is ignored (for now) for ease of exposition.

Producers offer digital access service plans at prices $P^{O_{T}^{B}}$. Offer prices are subscription contract prices set at the outset of the period, and the average price each customer pays is expressed as

$$
\bar{P}^{O_{T}^{B}}=\frac{P^{O} O_{T}^{B}}{N}
$$

where $P^{O_{T}^{B}} O_{T}^{B}$ are producer revenues from consumer sales of $N$ plans. Nominal consumer payments, $P^{S_{T}^{B}} S_{T}^{B}$ of equation (1) equals this producer sales revenue. We assume that producers' capacity is constrained in the short run (the period of the contract) and, after accounting for the usual issues regarding peak load planning, that producers set offer prices based on a preferred rate of capacity utilization determined by anticipated average customer usage, $\lambda^{a}$.

These assumptions imply that $O_{T}^{B}$ is a planned quantity of delivered services and not necessarily equal to $S_{T}^{B}$, the actual quantity of services consumed by users - unless of course actual usage $\lambda$ is perfectly anticipated, i.e., $\lambda^{a}=\lambda$. It follows that the offer price index $P^{O B}$ does not necessarily equal the consumption price index $P^{S_{T}^{B}}$ of equation (1). Let $u$ be an index of actual capacity utilization, where $u=1$ denotes the situation where $\lambda^{a}=\lambda$. We then have $\lambda=\lambda^{a} u$, in which case the relationship between real services consumption and real services offered, and between consumption prices and offer prices is given by

$$
\begin{gathered}
S_{T}^{B}=O_{T}^{B} u . \\
P^{S_{T}^{B}}=\frac{P^{O_{T}^{B}}}{u} .
\end{gathered}
$$

Equation 9 states that the consumption price index $P^{S_{T}^{B}}$ is a utilization-adjusted contract price.

Equations (8) and (9) are not very helpful for conventional, timely price measurement (as in a monthly CPI) because producers' preferred utilization rate $u$ is not readily observed. However, substitution of (8) into (9) reveals that the consumption price may be alternatively written as:

$$
P^{S_{T}^{B}}=\frac{P^{O_{T}^{B}} O_{T}^{B}}{S_{T}^{B}} .
$$


which suggests that consumption prices for access services may be obtained by dividing producer revenue by a relevant, consistently-defined volume measure, i.e., that ideally, $S_{T}^{B} \equiv$ VOL where VOL is such a measure.

What might that volume measure be? We know that total consumption increases along with the number of users and/or hours of use, but these are very coarse indicators that do not capture consumption intensity or service quality. An ideal measure would capture consumers' use in terms of the potential performance of communication networks and where utilized performance is a comprehensive measure capable of being consistently defined in the face of rapid technical change, e.g., Internet Protocol data traffic (IP) measured as optimally compressed megabytes/petabytes per year, i.e., that

$$
S_{B}^{T} \equiv \mathrm{VOL}=I P
$$

A range of services are delivered over networks, and dataflows/IP traffic may not always be the relevant indicator of quality, but for internet access services via computers of mobile phones IP traffic would appear to be a solid choice (e.g., see Abdirahman, Coyle, Heys, and Stewart, 2017). For video services, quality is not so simple; cross-country studies have found that the quality dimension for video services is captured by a range of controls, including the number of channels (HD and standard), and availability of premium channels and $4 \mathrm{~K}$ display resolution (Corrado and Ukhaneva, 2016, 2019; Díaz-Pinés and Fanfalone, 2015).

\subsection{Use intensity, $\lambda$}

With real services captured by a performance measure, the changes in network and device intensity of

use, $\dot{\lambda}$, can be shown to reflect the difference between changes in the average price paid by users for a plan and the price index for access services, i.e., it reflects changes in the quality of services consumed. To see this, log differentiate (2):

$$
\dot{\lambda}=\dot{S}_{T}^{B}-\dot{N}
$$


After adding and subtracting the nominal change in paid services, $P^{O_{T}^{\dot{B}}} O_{T}^{B}$, and combining terms, we obtain:

$$
\dot{\lambda}=\left(\frac{P^{O_{T}^{\dot{B}}} O_{T}^{B}}{N}\right)-\left(\frac{P^{O_{T}^{\dot{B}}} O_{T}^{B}}{S_{T}^{B}}\right)
$$

Substitution of (7) and (10) for the first and second terms yields:

$$
\dot{\lambda}=\dot{P}^{O_{T}^{B}}-\dot{P}^{S_{T}^{B}}
$$

In equation (13) the change in use intensity $\dot{\lambda}$ reflects the difference between the rate of change in a per user price and a unit volume price, or per equation (14), the difference between the rate of change in the price index for access services and rate of change in the average price per plan, i.e., quality change.

Statistical agencies generate price indexes in terms of offer prices $P^{O_{T}^{B}}$, not consumption prices $P^{S_{T}^{B}}$. Consider now the relationship between $\dot{\lambda}$ and the quality change in official price indexes for network access service (based on offer prices), e.g., quality change that might be captured using hedonic techniques that account for improvements in speeds and other capabilities in subscription telecom service plans 6 Noting first that the change in the offer price index, $P^{\dot{O}} \dot{T}_{T}^{B}$, also can be decomposed into the rate of change in quality of offered plans, $\dot{\nu}$, and the rate of change in the average price per plan, $\dot{P}^{O_{T}^{B}}$, i.e., $\dot{P}^{\dot{O}_{T}^{B}}=\dot{P}^{O_{T}^{B}}-\dot{\nu}$. Next, from log differentiation of (9), after subtracting the result from (14) and combining terms, the relationship between $\dot{\nu}$ and $\dot{\lambda}$ is readily shown as

$$
\dot{\lambda}=\dot{\nu}+\dot{u}
$$

which says that the quality change in real network access services consumption is equal to the quality change in offered plans (at offered prices) plus the unanticipated change in network service provider utilization.

\subsection{Network utilization, $u$}

Consider now how one might measure $u$. We do not need to measure $u$ to measure prices for consumer digital services, but knowing $u$ helps us interpret and analyze them. For example, knowing the direction

\footnotetext{
${ }^{6}$ As done, e.g., at the BLS (see Williams, 2008).
} 
of change in $u$ helps to understand how little change in measured quality change in contract prices $(\nu)$ might coexist with notable declines in consumption prices for network access services $\left(P^{S_{T}^{B}}\right)$; per equation (15), this situation occurs when there are notable increases in both household use intensity $(\lambda)$ and network utilization $(u) !^{7}$

As previously indicated, private industry capital income is generally understood to include a utilization effect, and previous work has considered how to extract a measure of network capital utilization from productivity data for internet service providers, or ISPs (Corrado, 2011; Corrado and Jäger, 2014; see also Corrado and van Ark, 2016). The basic idea in these works is that when an ex ante approach is used to determine an industry's return, a utilization factor can be calculated so as to exhaust observed capital income - provided that the industry's aggregate net stock of capital is not particularly sensitive to composition differences in asset use, i.e., it acts more or less as a single capital good Berndt and Fuss, 1986; Hulten, 1986). This is arguably the case for network services providers in the United States, whose capital stock is a physical network whose parts largely operate as a single good. Employing this assumption, Corrado (2011) found a substantial difference between the U.S. ISP industry's ex post calculated nominal rate of return and the market interest rates typically used in ex ante productivity analysis; the difference was able to be interpreted as network utilization.

The network services-providing industry's ex post gross return is defined as

$$
\Phi^{I S P}=\left(r^{I S P}+\delta^{I S P}-\pi^{I S P}\right)
$$

where $r^{I S P}$ is an ex post nominal net return determined residually (e.g., as in Jorgenson and Griliches, 1967), given depreciation $\delta^{I S P}$ and revaluation of the industry's capital stock $\pi^{I S P}$. Now define the industry's ex ante gross return as

$$
\bar{\Phi}^{I S P}=\left(\bar{r}+\delta^{I S P}-\pi^{I S P}\right)
$$

where $\bar{r}$ is an ex ante nominal rate of interest. Let $u^{I S P}$ be the industry's capital utilization rate. As shown in Appendix section A1, this utilization rate is given by

$$
u^{I S P}=\frac{\Phi^{I S P}}{\bar{\Phi}^{I S P}}
$$

\footnotetext{
${ }^{7}$ On the other hand, quality-adjusted contract prices are likely mis-measured when there is little change in $u$ in the face of increases in household use intensity.
} 
which suggests that the underlying relationship between the ex post and ex ante net rate of return, i.e., $r$ versus $\bar{r}$, for an industry or sector is an indicator of its capital utilization 8

\subsection{Summary}

To summarize, changes in the quantities and prices of consumer digital services as set out in equation (1) are as follows:

$$
\begin{aligned}
\dot{S}_{T}^{H} & =\dot{K}_{T}^{H}+\dot{\psi} \\
\dot{P}_{T}^{H} & =P_{T}^{\dot{I}} \\
\dot{S}_{T}^{B} & =\dot{V o l} \\
\dot{P}^{S_{T}^{B}} & =\dot{P}_{T}^{\dot{O}_{B}}-\dot{\lambda} .
\end{aligned}
$$

where $\lambda$ and $\psi$ were defined above, and $P_{T}^{I^{H}}$ is a quality-adjusted asset price index for network access equipment.

\section{Measurement}

This section summarizes how the prices and quantities of the previous section are measured and presents some key results. We begin with the new network access services price index, describing how this index may be built using alternative volume measures. We then present results for $\dot{\lambda}$ and for our calculations of utilization from the business side, $\dot{u}$. A second subsection sets out how our consumer digital capital stocks, their connectivity use rates, and digital capital services are obtained.

\subsection{Access prices, household use intensity, and network utilization}

We calculate a price index for four types of IT services provided to households by the business sectorcable, internet, mobile, and video streaming services-by dividing nominal spending for each service type $(j)$ by a measure that reflects the quality-adjusted time spent using the service, i.e., an appropriate $V O L$ for each $j$. The quality-adjusted price indexes by service type are aggregated to create an overall access price index that, when used to deflate total spending on access services, captures real access services consumption.

\footnotetext{
${ }^{8}$ In models that introduce imperfect competition in an otherwise standard neoclassical growth framework (e.g., Rotemberg and Woodford, 1995), utilization is absorbed in a more general inefficiency wedge capturing, among other things, the ability of firms to maintain a price markup.
} 
For exposition and analysis, we consider price indexes constructed using four alternative measures of quantity: the number of households subscribed to the service, the number of individual users, time spent on the service, and time spent adjusted for quality (our ultimate measure). The four alternative price and volume concepts will be indexed by $k$. Thus four alternative price indexes for each service type are calculated by dividing revenue for the service type by the four alternative volume measures, yielding prices paid per household $(k=H)$, per individual $(k=I)$, per unit of time $(k=D)$, and per unit of constant-quality time $(k=Q)$, i.e., we have $P_{H}^{S_{T}^{B}}, P_{I}^{S_{T}^{B}}, P_{D}^{S_{T}^{B}}$, and $P_{Q}^{S_{T}^{B}}$ for each service type $j$. (Note: $D$ is the notation used for time, i.e., as in hours per $\underline{D}$ ay).

The alternative price indexes are calculated as follows: Let $\left(P^{O_{T}^{B}} O_{T}^{B}\right)_{j}$ be payments for service type $j$ within total payments $P^{O_{T}^{B}} O_{T}^{B}$. Price change for price index concept $k$ covering all $J$ types of services is then

$$
\Delta \ln P_{k}^{S_{T}^{B}}=\sum_{j=1}^{J} \bar{w}_{j} \Delta \ln \left(\frac{P^{O_{T}^{B}} O_{T}^{B}}{\mathrm{VOL}_{k}}\right)_{j} \quad \text { where } \quad k=H, I, D, Q
$$

$\bar{w}_{j}$ is a Divisia payments share for digital access service type $j$, and $\mathrm{VOL}_{k, j}$ is service type $j$ 's volume measure corresponding to price index concept $k$. In terms of the framework set out in section 2 , we thus have the following:

$$
\begin{aligned}
\Delta \ln P^{S_{T}^{B}} & =\Delta \ln P_{Q}^{S_{T}^{B}} \\
& \dot{\lambda}=-\left(\Delta \ln P_{Q}^{S_{T}^{B}}-\Delta \ln P_{H}^{S_{T}^{B}}\right)
\end{aligned}
$$

Note that the suite of indexes constructed along margins of use enables changes in the quality-adjusted price index to be decomposed into contributions from $I, T$, and $Q$-i.e., into contributions from growth in individuals per household using the service, time spent on the service per individual user, and the quality of an hour of use of the service, respectively. Appendix section A2 documents the data sources for each price concept for each access service price index, including reporting the time series for prices by access service type and aggregate prices for each alternative measure of volume. Note that the contract price $P^{O_{T}^{B}}$, the price observed by the consumer, is not needed for the calculations (or analysis) in this paper 9

\footnotetext{
${ }^{9}$ Depending on the contract arrangement, the price observed by the consumer may correspond to any of the four price concepts we consider. For example, if a consumer pays a cable company a fixed amount to keep the household connected each month, $P^{O_{T}^{B}}$ equals $P_{H}^{S_{T}^{B}}$. If a consumer pays an internet provider a fixed amount to have unlimited access each month, $P^{O O_{T}^{B}}$ equals $P_{I}^{S_{T}^{B}}$. If the consumer has a prepaid plan for a certain number of hours of talk time on a feature phone, $P^{O_{T}^{B}}$ equals $P_{D}^{S_{T}^{B}}$. And, if the consumer has a contract for smartphone use based on data traffic consumed, $P^{O_{T}^{B}}$
} 
Figure 3: Network Access Services Price Change and Use Intensity

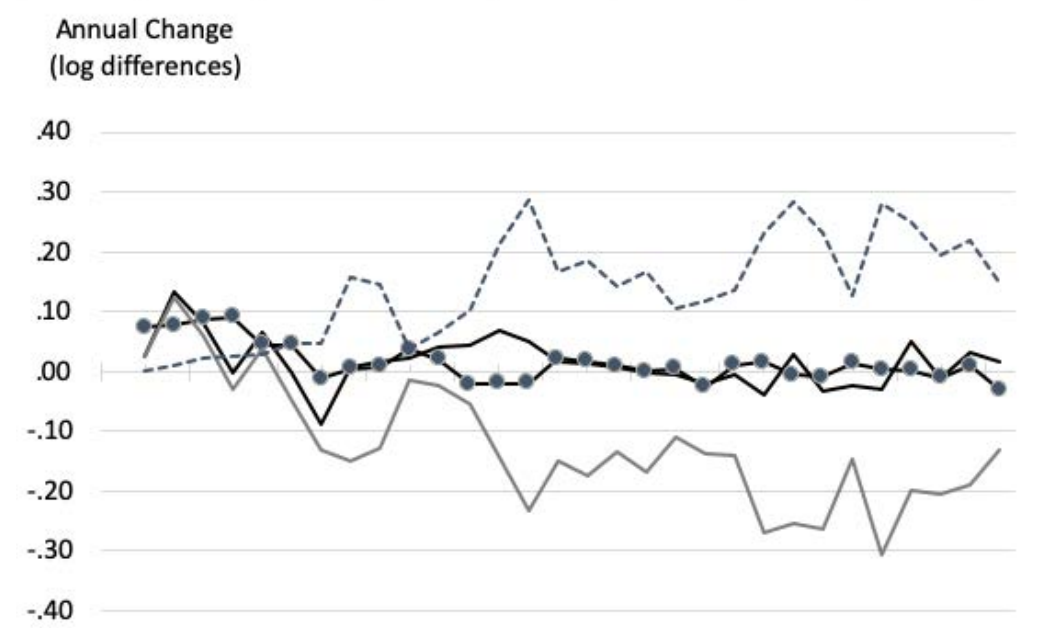

- Average price per household $\quad$ - - Network Access Price (BEA)

- Network Access Price (this paper) ----. Household use intensity

The aggregate quality-adjusted price index for access service corresponding to equation (21), shown as the solid gray line in figure 3, falls 12.4 percent per year (average annual rate) over the full period of this study. Household use intensity, $\dot{\lambda}$ per equation $(22)$ and also shown, increases 13.9 percent at an annual rate. Figure 3 also shows a price index for network access services constructed using components of BEA's PCE price index and our per household price index (i.e., the average price per household, $P_{H}^{S_{T}^{B}}$ ). Note first that our new access services price index (the gray line) falls much faster than the implicit price index in existing GDP (the black line); the growth implications of this finding will be reviewed in the next section of this paper. Note second that changes in the BEA price index hovers about changes in our per household price from about 2000 on; if the BEA index accurately represents changes in contract prices, the result implies that there is very little quality change in measured offer prices from from 2000 to 2017, i.e., $\dot{\nu}$ has shown essentially no change since 2000.

Results for the overall price index by sub-periods are plotted in panel (a) of figure 4 spending shares for its subcomponents by type are shown in panel (b) of the figure. As may be seen, the decline in the quality-adjusted network access price index accelerates over time, first as internet service accounts for a rising share of spending (1997 to 2007), then as smartphone access becomes more important (2007 to 2017).

The trends in the aggregate network access price index also reflect large differences in the contributions by access mode, shown in figure 5. Contributions to the overall volume price change by each intensity margin (i.e, volume measure) show the following. First, there is little difference between changes in per individual user prices relative to per household prices; as a result, only the contribution of changes in the price per household shows

equals $P_{Q}^{S_{T}^{B}}$. This information is not needed to construct our price indexes, even though these details are required for official prices based on contract arrangements. 
Figure 4: Network Access Services Price Index

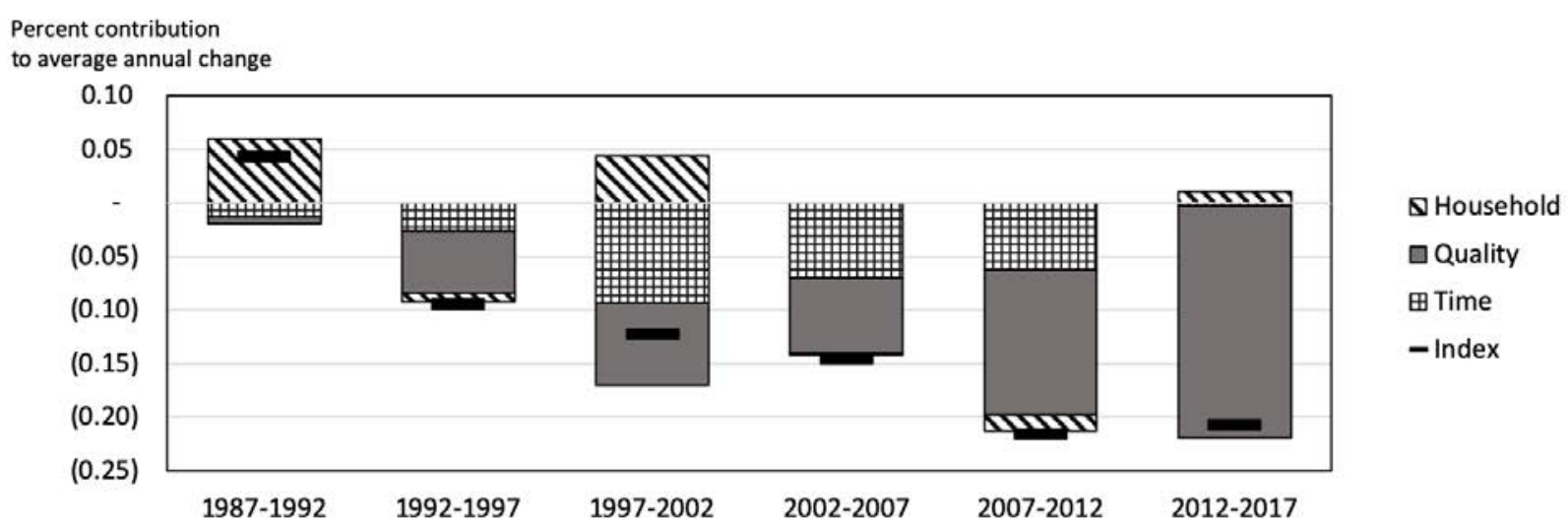

(a) Contributions to Price Change by Volume Measure

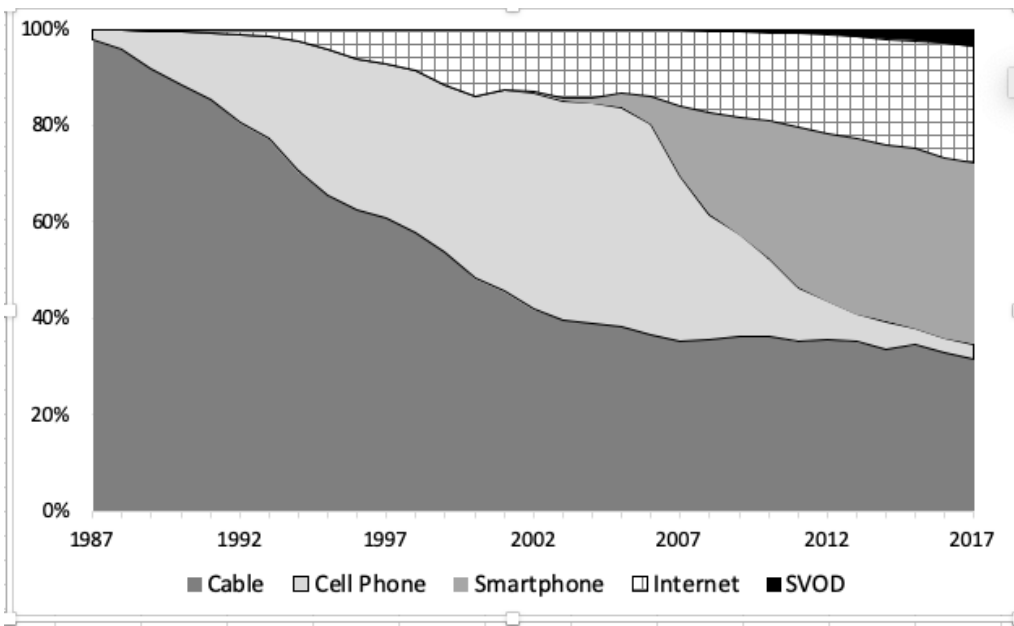

(b) Shares of Spending by Mode of Network Access

through in figure 4. Second, quality change contributes significantly to the overall decline in network access prices in most sub-periods. Third, consumers' increase in time connected provides a substantial, additional kick from 1997 to 2012; time connected is especially important in driving price change for mobile and SVOD services.

Finally, given that both usage trends and technological change are major drivers of the drops in our network access price index, we calculate values for producer network utilization $u$ in light of the fact that figure 3 suggested there was very little (measured) quality change in official access prices since 2000. As previously discussed, $\dot{\lambda}$ will reflect trends in consumer usage as well as technological improvements in content delivery systems measured on the basis of contract prices. Our calculation of $u$ is detailed in Appendix section A1, and figure 6 shows the result, which covers the period from 2000 to 2016. While the utilization measure bounces about year by year, it rises more than 4-1/2 percent per year, on balance. This pattern is interesting for several reasons-but 
Figure 5: Price Decompositions by Mode of Network Access

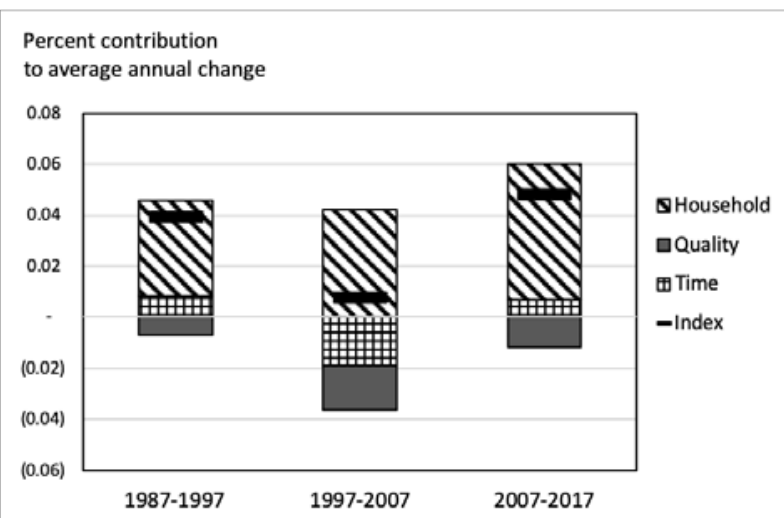

(a) Cable

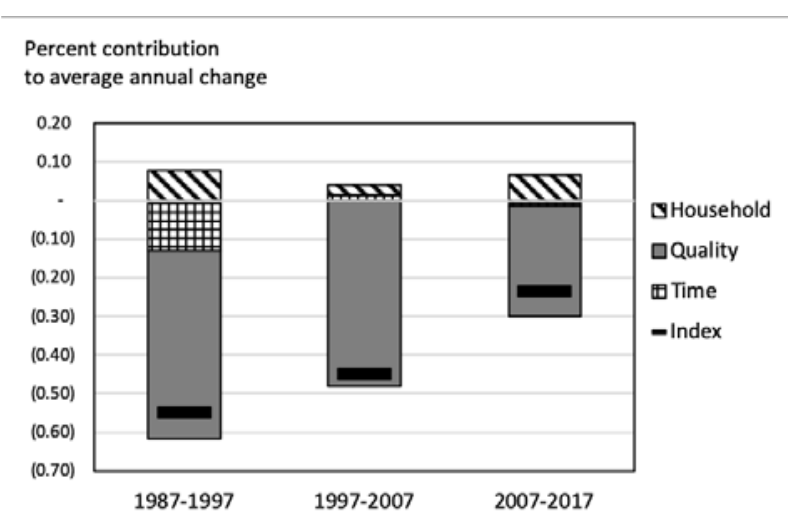

(c) Internet

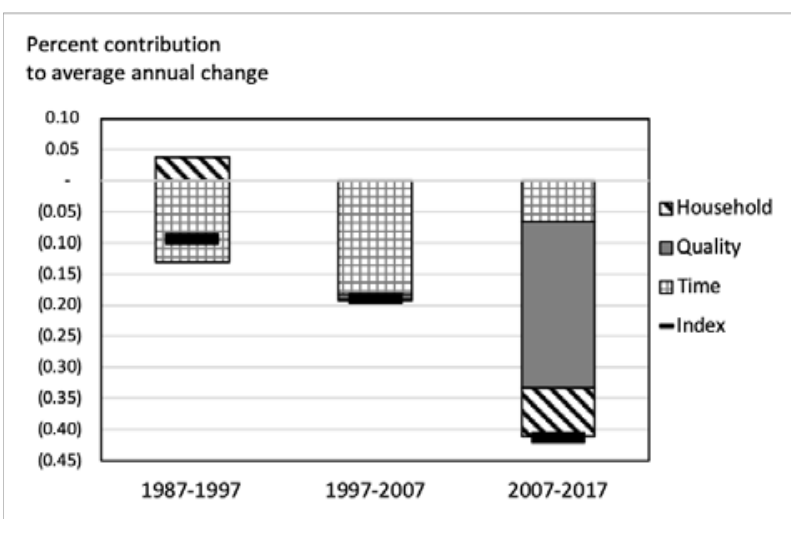

(b) Mobile

Percent contribution

to average annual change

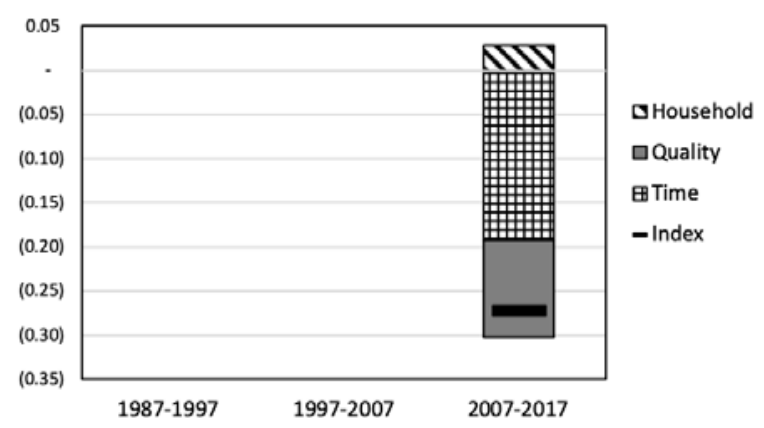

(d) SVOD

before we offer our interpretation, note that the measure in figure 6 pertains to the entire telecommunications and broadcasting industry, i.e., it includes commercial and enterprise customers and thus does not solely reflect the interaction between the demand and supply of consumer content delivery services as defined in this paper. That said, per equation (15), the rather sharp rise in $u$ supports our decomposition showing that a significant fraction of the large divergence between $\dot{\nu}$ and $\dot{\lambda}$ after 2000 reflects increases in use rates. In terms of the model of section $2, \lambda$ consistently exceeded $\lambda^{e}$ and lowered the effective price paid by each consumer (holding per plan quality constant) ${ }^{10}$

\footnotetext{
${ }^{10}$ Seen from another perspective, the rise in $u$ reflects strengthening industry profitability and pricing power. On a per household basis, changes in households' average prices actually decelerated (or fell) after 2002 relative to earlier experience (see again figure 4), suggesting that the rise in relative profitability reflected a prolonged positive demand shock, i.e., consistent with a situation in which $\lambda$ consistently exceeded $\lambda^{e}$.
} 
Figure 6: Implied Network Utilization

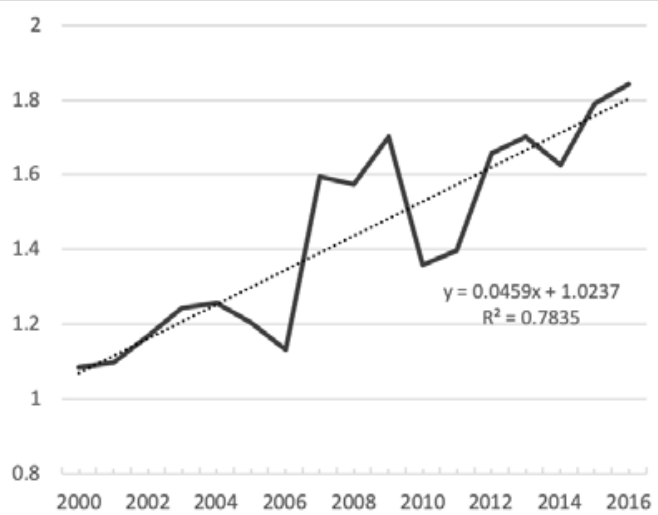

\subsection{Digital Net Stocks, Capital Services, and Asset Prices}

Table 1: PCE durable digital goods

\begin{tabular}{|c|c|c|c|}
\hline & Product class & Depreciation Group $^{a}$ & NAE Group ${ }^{b}$ \\
\hline & $(1)$ & $(2)$ & (3) \\
\hline 1. & Televisions & A & $\mathrm{Y}$ \\
\hline 2. & Cameras & B & $\mathrm{N}$ \\
\hline 3. & Other photographic equipment & A & $\mathrm{N}$ \\
\hline 4. & Other video equipment & A & $\mathrm{N}$ \\
\hline 5. & Audio equipment & A & $\mathrm{N}$ \\
\hline 6. & Recording media & A & $\mathrm{N}$ \\
\hline 7. & Computers & B & $\mathrm{Y}$ \\
\hline 8. & Data storage equipment & B & $\mathrm{Y}$ \\
\hline 9. & Monitors & B & $\mathrm{Y}$ \\
\hline 10. & Computer peripherals & B & $\mathrm{Y}$ \\
\hline 11. & Miscellaneous office equipment & A & $\mathrm{N}$ \\
\hline 12. & Software and accessories & B & $\mathrm{Y}$ \\
\hline 13. & Cell phones & B & $\mathrm{Y}$ \\
\hline 14. & Other telephone and communications equipment & A & $\mathrm{N}$ \\
\hline
\end{tabular}

Notes: a. $A=9$ year service life, $B=5$ year service life. $b . N A E=$ Network Access Equipment.

In this section we set out our measures of consumer digital services based on "connected" IT capital stocks. Table 1 column (1), lists the 14 product classes of durable goods considered to be consumer durable digital (or IT) goods. This list ranges from TVs, to computers and software, to cell phones ${ }^{11}$ Consumer spending for most of these products may be developed from underlying detail in the U.S. national income and product accounts (NIPAs); indeed, the first 12 product classes shown in the table directly correspond to categories of digital goods

\footnotetext{
${ }^{11}$ Game consoles, which have embodied massive innovation in the period of this study, are not included for lack of data.
} 
reported in the annual personal consumption expenditures (PCE) bridge table ${ }^{12}$ For the analysis in this paper, estimates of the retail value of consumer cell phone purchases are developed from industry sources; see Appendix section A3 for further details on how this series and the other telephone equipment series are estimated.

In terms of service lives, the products are grouped into two categories, those with a 9 year service life (A) and those with a 5 year service life (B). These groupings are indicated in column (2) of the table, and are a (slight) simplification of the service life categories used by BEA in their fixed asset accounts ${ }^{13}$ To compute net stocks we follow BEA and Hulten and Wykoff (1981a b) and use a declining-balance rate of 1.65 for these goods, which implies geometric rates of depreciation of .1833 and .3300 for groups A and B, respectively. An end-of-year (EOY) net stock of each product class $a$ in table1 1 is calculated using the perpetual inventory method with geometric depreciation, again following BEA (see page M-7 in U.S. Department of Commerce. Bureau of Economic Analysis, 2003):

$$
K_{a, E O Y}^{H}=I_{a, t}^{H}\left(1-\frac{\delta_{a}^{H}}{2}\right)+\left(1-\delta_{a}^{H}\right) K_{a, E O Y-1}^{H}
$$

where $I_{a, t}^{H}$ is annual real investment for each asset class $a$ in year $t$.

When considering the demand complementary of payments for digital access services with stocks of the devices shown in table 1, only the equipment used for cable TV, subscription video, internet or mobile network access is relevant. Column (3) of the table is an indicator of whether the asset class is included in the NAE stocks relevant to the analysis in this paper, i.e., whether the stocks are included in $K_{T}^{H}$. As may be seen, three types of equipment require estimates of use intensity: televisions, computers, and cell phones. To obtain "effective" NAE stocks, an estimate of their use intensity $\psi_{a}=D e v_{a} / D^{*}$ per equation (4) is required. These equipment use intensities allow us to identify the stock of IT capital that yields services corresponding to the unpriced portion of households' consumption of digital content over networks. We first summarize the construction of $\psi_{a}=D e v_{a} / D^{*}$, and then we present our estimates of unpriced services $P^{S_{T}^{H}} S_{T}^{H}$ per equation $5 \mathrm{~b}$.

Our estimates of equipment use intensity begin with our time-based estimates of average household time spent using each access service, panel (a) of figure 7. We then measure the share of households with at least one of each device and the number of devices in use conditional on the household having such a device (panels $\mathrm{b}$ and $\mathrm{c}$ ). The total number of hours households spend on each device is calculated from these elements, which also requires allocating time spent on accessing each digital service to the capital used for the access. The result expressed as the share of the day each device type is in use $\left(\psi_{a}\right)$ is shown in panel (d). Additional details and data sources for this calculation are spelled out in Appendix section A4.

\footnotetext{
${ }^{12}$ BEA's annual PCE bridge table begins in 1998 and does not extend through the most recent NIPA year. Nine categories of PCE spending on digital goods are reported on NIPA table 2.4.5U, however, and these data are used to develop the more detailed, bridge table-based series from 1970 to 1997 and for the year 2017.

${ }^{13}$ Compared BEA's methods, the major simplification we make is to use geometric depreciation for computers.
} 
Figure 7: Time-based Equipment Use Intensity

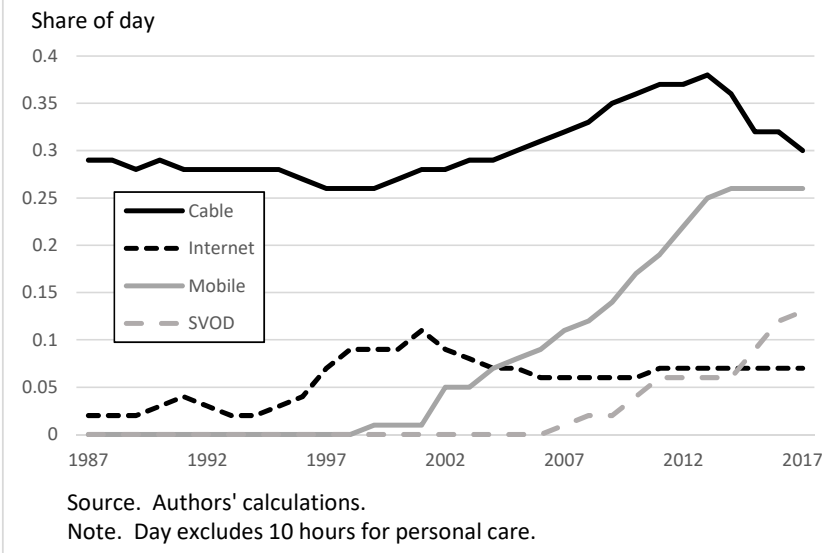

(a) Access Service Use Intensity

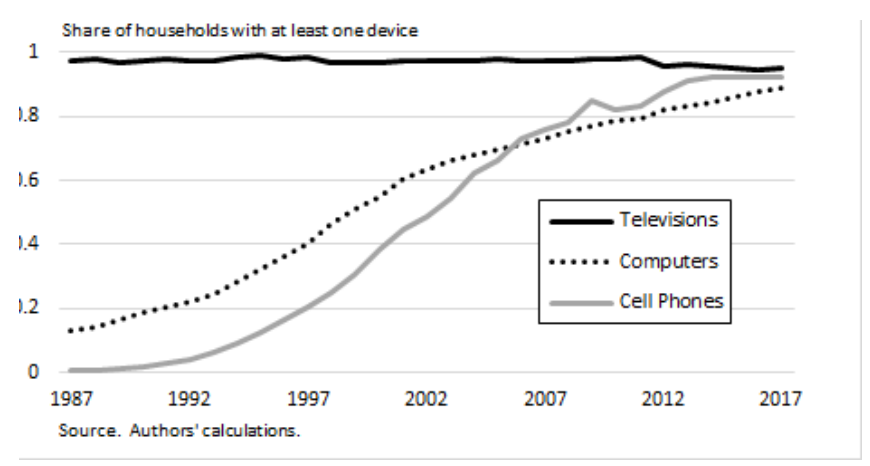

(b) Device Penetration

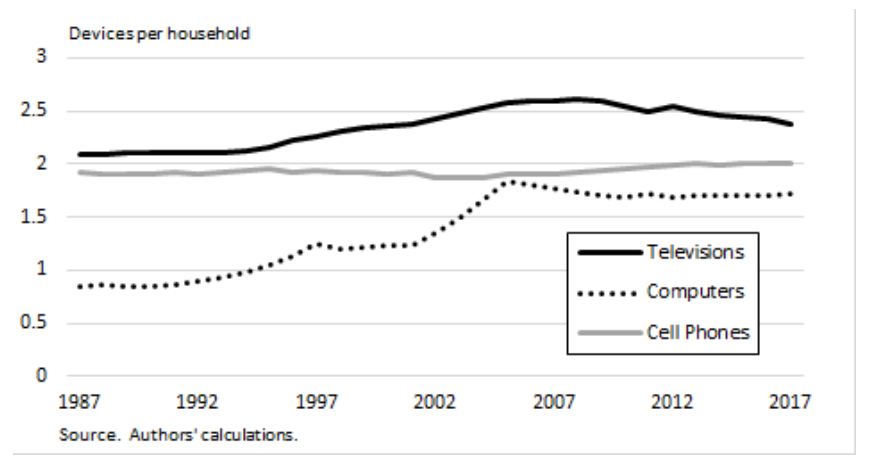

(c) Device Multiplicity

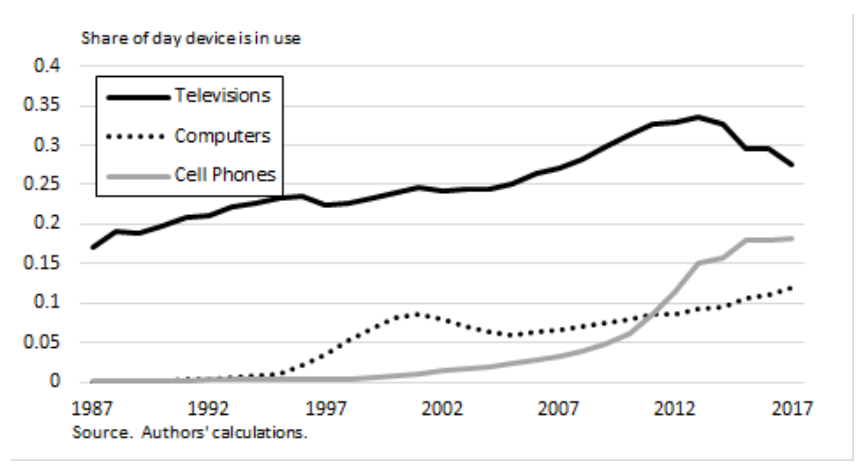

(d) Device Use Intensity $\left(\psi_{a}\right)$ 
To calculate $P^{S_{T}^{H}} S_{T}^{H}$, we proceed as follows: The nominal value of the capacity flow of services from each consumer digital asset is calculated via equation (3) with the gross ex ante rental rate formed using the 10year constant-maturity government bond rate, the relevant depreciation rate as described above, and actual price change for each asset type ${ }^{14}$ Then we (a) sum over all asset types to obtain an estimate of consumer capital services based on total digital goods stocks and (b) sum over the asset types included in network access equipment to obtain the subcomponent for services from total NAE stocks. Finally, we (c) adjust the capacity NAE services for the extensive margin (i.e., we apply our estimates of $\psi_{a}$ ) to obtain actual capital services generated via households' use of IT goods purposed for accessing digital networks, i.e., capital services from the effective NAE stocks. The results of (a), (b), and (c) are shown in figure 8, plotted relative to GDP adjusted to include them.

Our estimate of home-generated digital services relative to GDP, the solid black line in figure 8 , rises steadily over the thirty years shown in the figure, reflecting both the increase in relative importance of NAE stocks in all digital stocks (the black dotted line versus the thin gray line) and the increased portion of NAE stocks connected to networks (the solid versus dashed black lines) that reflects the increase in $\psi$. The ratio of $P^{S_{T}^{H}} S_{T}^{H}$ relative to GDP stood at 1.04 percent of GDP in 2017, up from .48 percent ten years earlier. This trajectory is roughly similar to estimates of free services prepared using a very different approach (the open dots in the figure) ${ }^{15}$

The real investment used to develop net stock estimates via equation 23 is calculated by deflating nominal spending on each product class using asset price indexes based on the sources documented in the appendix. These prices are research indexes largely adapted from prior work (Byrne and Corrado, 2015a b; Byrne, 2015. Byrne and Corrado, 2017a b). In new moves, we incorporate two quality-adjusted price indexes from Statistics Japan and exploit work by Copeland (2013) on consumer game software in combination with results from the Bureau of Labor Statistics producer price index for game software. Our price index for the 14 consumer digital goods listed in table (1) falls 11.7 precent per year from 2007 to 2017, 2.6 percentage points faster than its official counterpart (based on published PCE prices); see Appendix section A3 for further details.

The implicit deflator for consumer digital assets depends on the weighting of the components in the effective NAE aggregate. Figure 9 shows annual price for total NAE stocks versus effective NAE stocks. As may be seen, the weighting of the underlying components produces very similar results for effective NAE stocks versus a simple aggregate of those stocks. Our price index for home services, $P^{S_{T}^{H}}$, is the Jorgensonian rental price index for effective NAE stocks (the solid line in the figure), which is driven by the appropriately weighted asset price (the dotted line). The effective NAE rental price fell 12.5 percent per year over the full period of our study and dropped 17.2 percent from 2007 to 2017.

\footnotetext{
${ }^{14}$ In the implementation of (3), mid-period stocks computed from EOY stocks are used.

${ }^{15}$ Nakamura et al. (2018) estimate the costs of producing both professionally-created and user generated consumer content. The black open dots in the figure are their estimates for the digital component of their professionally-created free content plus their estimate of the value of user-generated free content.
} 
Figure 8:

\section{Consumer Digital Capital Services,}

Nominal Estimates from 1987 to 2017

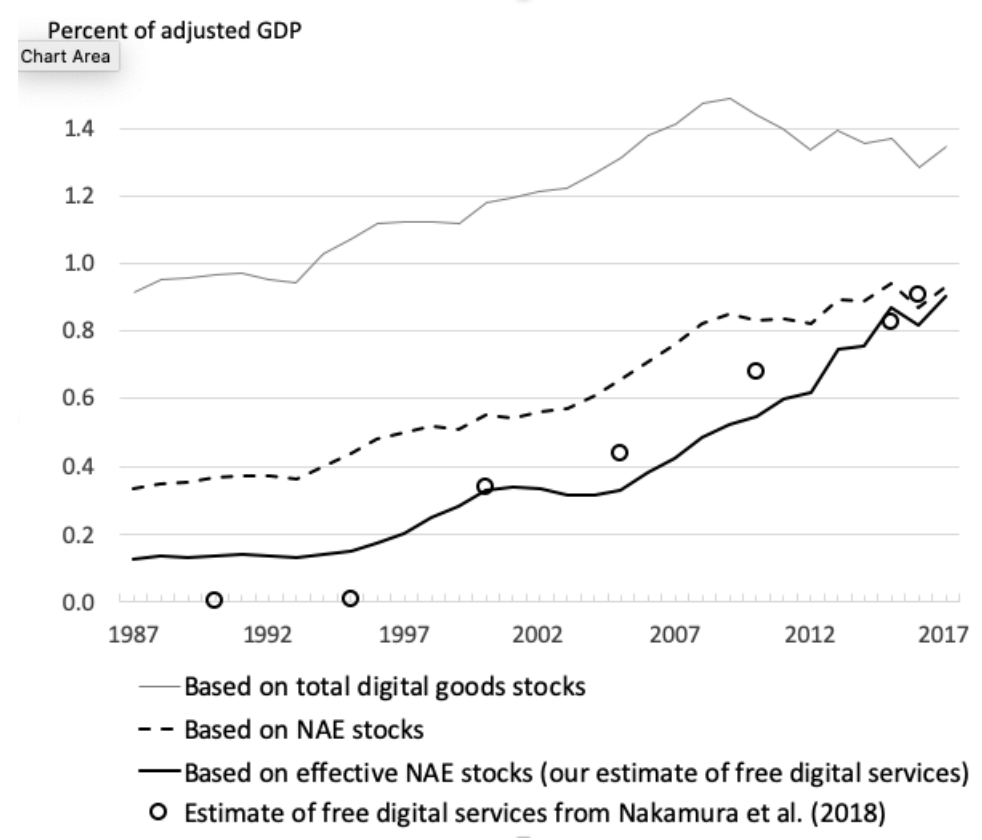

Figure 9:

Consumer Digital Asset Prices,

Annual Price Change 1988 to 2017

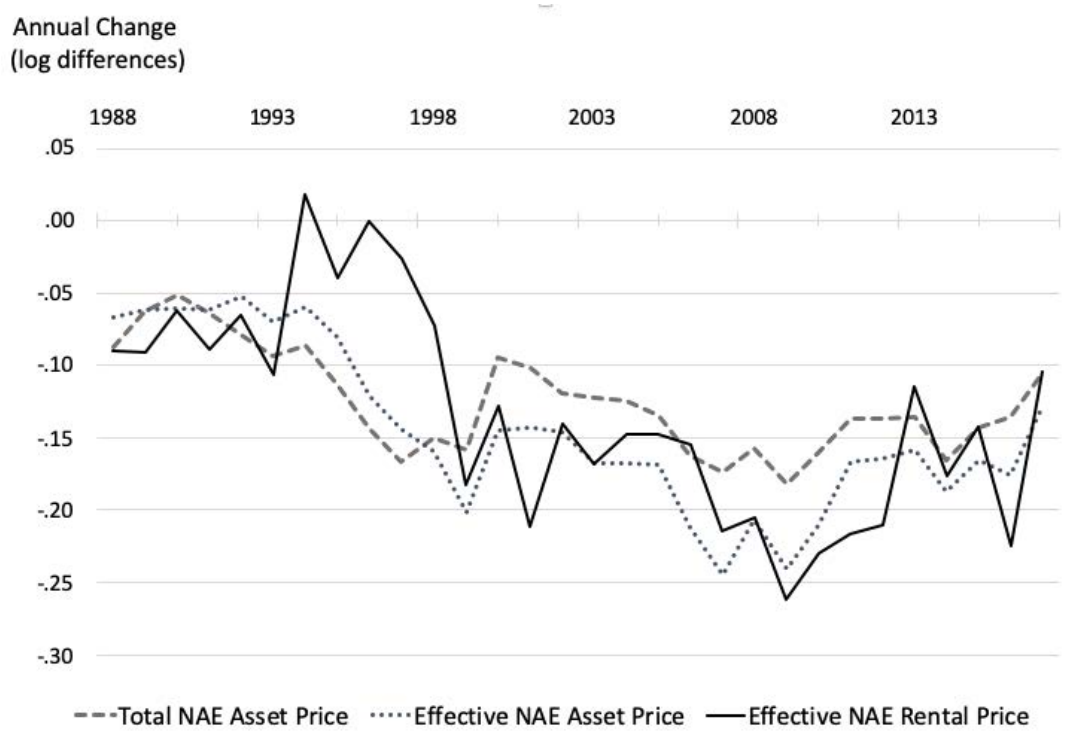

SOURCE: Elaboration of price indexes developed for this paper. 


\subsection{Summary}

Our new estimates of digital services consumption consist of two components, a paid-for network access services component and an imputed connected IT capital services component. The price index for network access services was reviewed in section 3.1. To obtain real spending, we delate nominal figures from the national accounts published by Bureau of Economic Analysis, incorporating some additional detail as explained in Appendix section A2.

The imputed component was reviewed in section 3.2 . The new nominal spending measure was developed as a capital services flow derived from the effective NAE stocks shown in figure 8 . The price deflator is then the corresponding rental price, displayed in figure 9.

\section{Results and Implications}

This section reports the new real digital services consumption measures and discusses their implications for real GDP and consumer surplus.

\subsection{GDP}

Our results for GDP are summarized in the table below. These results are calculated under the conservative assumption that overall real GDP is unaffected by differences the PCE IT goods investment price indexes developed in this paper and official prices used in GDP because these goods are primarily imported (whether for "effective" investment or all IT goods spending); recall too that we are unable to include the rapid quality change in game consoles in our price indexes.

The key takeaways from table 2 are, first, as shown on line 2, column (1), real services from use of connected digital systems grow very strongly, averaging 26.2 percent per year for the full period of the study. Second, our new results for real access services (line 4) are also very strong; as shown in column (5), real growth averaged nearly 34 percent per year during the Great Recession and its immediate aftermath (i.e., from 2007 to 2012). Third, this paper's approach to accounting for innovation in consumer digital services shows that it is possible to "see" digitalization in GDP. If our methods were to be incorporated in the national accounts of the United States, the contribution of consumer digital services (both components) to real GDP growth would average .57 percentage points from 2007 to 2017 (line 7, column 4), and annual real GDP growth would be 46 percentage points per year higher (line 7a, column 4).

The GDP impacts shown in table 2 are substantial. As reported and analyzed elsewhere (Byrne and Corrado, 2020), the impacts of our new digital services price indexes on overall consumer/PCE price inflation also are substantial. 
Table 2: Changes in Consumer Digital Services, 1987 to 2017

\begin{tabular}{|c|c|c|c|c|c|c|}
\hline & $\begin{array}{l}1987 \text { to } \\
2017\end{array}$ & $\begin{array}{c}1987 \text { to } \\
1997\end{array}$ & $\begin{array}{c}1997 \text { to } \\
2007\end{array}$ & $\begin{array}{l}2007 \text { to } \\
2017\end{array}$ & $\begin{array}{c}2007 \text { to } \\
2012\end{array}$ & $\begin{array}{c}2012 \text { to } \\
2017\end{array}$ \\
\hline Percent change, annual rate & $(1)$ & $(2)$ & (3) & (4) & (5) & (6) \\
\hline \multicolumn{7}{|l|}{ Capital services: } \\
\hline 1. Nominal & 11.9 & 10.9 & 13.6 & 11.2 & 10.5 & 11.9 \\
\hline 2. Real & 26.2 & 18.1 & 29.5 & 31.2 & 33.7 & 28.8 \\
\hline \multicolumn{7}{|l|}{ Access services: } \\
\hline 3. Nominal & 11.5 & 15.1 & 13.3 & 6.2 & 7.7 & 4.7 \\
\hline 4. Real & 26.2 & 18.1 & 29.5 & 31.2 & 33.7 & 28.8 \\
\hline \multicolumn{7}{|l|}{ Memos: } \\
\hline \multicolumn{7}{|l|}{ Effective NAE investment: } \\
\hline 5. Nominal & 12.2 & 10.5 & 15.6 & 10.5 & 11.2 & 9.8 \\
\hline 6. Real & 27.9 & 19.4 & 37.8 & 32.4 & 35.6 & 29.3 \\
\hline \multicolumn{7}{|l|}{ Contrib. to $G \dot{D} P^{a, b}$} \\
\hline 7. Consumer digital services & .33 & .09 & .30 & .57 & .57 & .59 \\
\hline Net of existing & .25 & .05 & .17 & .46 & .38 & .54 \\
\hline Capital services & .09 & .02 & .06 & .17 & .15 & .19 \\
\hline Access services $^{b}$ & .24 & .07 & .24 & .40 & .40 & .40 \\
\hline Net of existing & .16 & .03 & .11 & .29 & .23 & .34 \\
\hline
\end{tabular}

Notes: a. Percentage points. c. GDP contributions are calculated assuming that differences between PCE digital goods investments and their price indexes and their official counterparts have no impact on existing GDP because they are largely imported.

With regard to changes in the trend rate of real GDP growth, the impact of using our framework for measuring consumer digital services boosts the rate of real GDP growth from 2007 to 2017 relative to ten years earlier (1997 to 2007) by .29 percentage point (line 7a, column 4 less column 3) - a notable acceleration. Both the GDP boundary expansion (adding imputed real digital capital services) and the adoption of a qualityadjusted consumption price index for network access services contribute to this acceleration, with about 60 percent stemming from the net contribution of the new access services price index (.16 percentage point). The latter contribution also boosts business productivity growth; as with services from owner-occupied housing, the imputation for self-generated digital capital services is not factored into conventional measures of productivity change.

\subsection{Consumer Surplus}

The consumer surplus stemming from innovations in consumer content delivery can be calculated using an index number approach if the quality-adjusted price indexes used in the analysis fully capture the benefits of the changes in question. Assuming our price indexes are up to the task, we compute consumer surplus as the 
macroececonomic gain from the relevant continuing commodities following (Diewert and Fox, 2017) as:

$$
.5\left(\Delta \Pi^{S_{T}^{H}} \Delta S_{T}^{H}\right)+.5\left(\Delta \Pi^{S_{T}^{B}} \Delta S_{T}^{B}\right)+.5\left(\Delta \Pi_{T}^{I_{T}^{e H}} \Delta I_{T}^{e H}\right)
$$

where $\Delta$ is a long difference, and the $\Delta \Pi$ 's are changes in the relative prices, i.e.,

$$
\Pi^{S_{T}^{H}}=\frac{P^{S_{T}^{H}}}{P^{P C E}} \quad, \quad \Pi^{S_{T}^{B}}=\frac{P^{S_{T}^{B}}}{P^{P C E}} \quad \text { and } \quad \Pi^{I_{T}^{e H}}=\frac{P^{I_{T}^{e H}}}{P^{P C E}} \quad,
$$

where $P^{P C E}$ is the overall price index for consumer spending.

In the textbook exposition of consumer surplus, the price drop from the Hicksian reservation price to the transaction price of the new good or service is the welfare gain stemming from the innovation in question. To fully capture this gain, benefits of individual innovations are quantified using techniques that rely on estimates of demand elasticities or estimated parameters of utility functions in conjunction with transactions prices and revenue data, e.g., Petrin (2002) and Greenwood and Kopecky (2013). There are many individual innovations underlying our price indexes, however, and for this reason alone, eschewing a parametric approach and using (24) has many advantages. Using (24) views innovations in digital content delivery as serial Schumpterian change where individual innovations are launched, gain market share, and then lose market share as another innovation is introduced. We believe this process is well captured by our quality-adjusted price indexes even though they do not explicitly incorporate Hicksian reservation prices. Our comprehensive accounting of use intensity captures the benefits of ubiquitous connectivity/networks cum powerful equipment in our estimates. Many of the products that undergird these estimates experience constant change via incremental quality improvements and introduction of new forms and varieties, and we are able to incorporate these changes, e.g., enhancements to personal computing via new forms (tablets and cell phones) and improvements in performance (speed, storage) are incorporated in our estimates 16

The results of computing (24) are presented in table 3 . Changes from the beginning of our sample (1987, arguably also the beginning of the Internet) to the beginning of social media and mobile broadband (taken as 2004) are assessed, as are changes from this point to 2017, the last year of our estimates. As may be seen on row 1, the consumer surplus due to innovations in digital content delivery from 1987 to 2004 (18 years) was nearly $\$ 900$ billion in 2017 dollars (column 1) and $\$ 5.8$ trillion over the next 14 years (column 2). These are substantial amounts. On a per user basis, rows 5 through 8 , the gain hovered at or slightly below $\$ 30,000$ (in

\footnotetext{
${ }^{16}$ Note further that even for an innovation as significant as the iPhone, the impact of the omission of Hicksian reservation prices on a price index is very small because the revenue weight on the unobserved initial price drop is likely to be so tiny that ignoring this change has very little impact GDP or consumer surplus. As reported in Apple's financials, total iPhone revenue in the quarter of introduction in 2007 was $\$ 8$ million ( $\$ 32$ million at an annual rate). GDP was $\$ 14,452$ billion and our digital services series was $\$ 278,334$ million in that year. One half of the revenue gain from the iPhone in its introductory quarter at an annual rate was then $.11 \times 10^{-5}$ relative to GDP and $.057 \times 10^{-3}$ relative to our series for connected digital capital services. Consider now the following thought experiment: Assume the change from the reservation price to the actual price of the iPhone was a ginormous - 1000 percent in the quarter of introduction. Then our price index would be off 5.7 percentage points in the initial quarter (1.4 percentage points for the year) but GDP would be essentially unaffected.
} 


\section{Table 3: Consumer Surplus from Innovations in Content Delivery Systems}

\begin{tabular}{|c|c|c|c|}
\hline & & $\begin{array}{c}1987 \text { to } 2004 \\
\text { (1) }\end{array}$ & $\begin{array}{c}2004 \text { to } 2017 \\
\text { (2) }\end{array}$ \\
\hline \multicolumn{4}{|c|}{ Surplus, in billions of 2017 dollars: } \\
\hline 1. & Digital goods and services, total & 892 & 5,841 \\
\hline 2. & Capital investment & 262 & 1,287 \\
\hline 3. & Capital services & 311 & 2,301 \\
\hline 4. & Access services & 319 & 2,254 \\
\hline \multicolumn{4}{|c|}{ Surplus, in thousands of $\$$ per user ${ }^{a}$ : } \\
\hline 5. & Digital goods and services, total & 27,320 & 30,294 \\
\hline 6. & Capital investment & 8,031 & 6,672 \\
\hline 7. & Capital services & 9,510 & 11,933 \\
\hline 8. & Access services & 9,779 & 11,689 \\
\hline \multicolumn{4}{|c|}{ Annual surplus per user: } \\
\hline & Digital goods and services, total & 1,607 & 2,330 \\
\hline 10. & Capital investment & 472 & 513 \\
\hline 11. & Capital services & 559 & 918 \\
\hline 12. & Access services & 575 & 889 \\
\hline
\end{tabular}

2017 dollars). While these numbers seem very large (implying a per user gain in economic welfare of more than $\$ 2,000$ per year, on average, during the latter period), they are in the same neighborhood as estimates of consumer surplus obtained by Brynjolfsson et al. (2019) using massive online choice experiments. The sum of their median willingness-to-pay estimates for the items included in their surveys (search engines, email, maps, video, e-commerce, social media, messaging, and music) was \$32,232 in 2017 (Brynjolfsson et al., 2019, table 7, sum of items in column 2).

We compare our long difference estimates with the single-point-in-time survey results of Brynjolfsson et al. (2019) based on a conjecture that respondents in their massive online experiments are thinking about what they would have to pay to "return" to life before social media, smart phones, and mobile broadband. Brynjolfsson et al. (2019) also report median willingness-to-pay estimates for a survey conducted in 2016, and these values sum to $\$ 26,150$, expressed in 2017 dollars 17 Using 24 with a long difference from 2004 to 2016 (i.e., dropping the last year, and dividing by a slightly lower number for the average number of users) yields an estimate of the consumer surplus of $\$ 24,676$ per user - again in the same ballpark and, we believe, strengthening our conjecture.

\section{Conclusion}

The household is an important locus of the digital revolution and one of its most visible since smartphones and social media became widespread. Entertainment, communication, and work from home have been supercharged

\footnotetext{
${ }^{17}$ The simple sum of their figures is $\$ 25,697$.
} 
by advances in hardware, software, and communication. Hardware innovation has proceeded at an especially blistering pace as the major household platforms - smartphones, tablets, televisions, gaming consoles and all the apps that run on them - have become extraordinarily powerful (and cheap) and as datacenter innovation (i.e. the cloud) has charged ahead in the background. Faster communication speeds - both wireline and wireless - have been essential of course; for example, nearly one-third of all IP traffic in 2016 was accounted for by Netflix alone, a usage volume not possible one or two years earlier.

The highly visible innovations in consumer content delivery raises the question of whether existing national accounts are missing consequential growth in output and income associated with content delivered to consumers via their use of digital platforms. The changing production border for digital content delivery suggests that GDP (as well as other macroeconomic measures, such as PCE prices) need to account for the substitution away from market-based digital services consumption. How and whether to address distortion to the production boundary created by the substitution between market activity and household activity is an old issue in national accounting, an issue that is often dismissed as second-order except for the case of owner-occupied housing.

We believe the digitization of consumer content delivery presents a first-order distortion to the production boundary of national accounts - and that an imputation for the omitted services from connected IT capital needs to be made to avoid imparting a bias to GDP. The case for imputing services from owner-occupied housing is based on the size of the omitted services and the importance of accounting for them in international comparisons. The case for imputing services from connected IT capital is based on the astonishingly fast relative growth of the omitted services in both real and nominal terms. As shown in the analysis of the contribution of business IT goods and services to real GDP growth set out in Byrne and Corrado, 2017b, even as the extensive aspects (e.g., hours per day) driving consumer digital services growth runs its course, access services and services from connected IT capital will continue to provide an extra kick to real GDP growth due their declining relative price.

All told, we estimate that consumer welfare due to growth in digital content consumption has been enhanced to the tune of $\$ 1,775$ per connected user per year from 2004 to 2017 (2017 dollars). And when the demand complementarity framework set out in this paper is incorporated into existing GDP, we find that real consumer digital services contributes nearly .6 percentage points per year to U.S. economic growth from 2007 to 2017, about 1/4 percent per year faster than its contribution from 1997 to 2007. 


\section{References}

Abdirahman, M., D. Coyle, R. Heys, and W. Stewart (2017). A comparison of approaches to deflating telecoms services output. Technical Report Discussion Paper 2017-04, ESCoE and ONS.

Aizcorbe, A., D. M. Byrne, and D. E. Sichel (2019). Getting smart about phones: New price indexes and the allocation of spending between devices and services plans in personal consumption expenditures. Working Paper No. 25645, National Bureau of Economic Research.

Berndt, E. R. and M. A. Fuss (1986). Productivity measurement with adjustments for variations in capacity utilization and other forms of temporary equilibrium. Journal of Econometrics 33(1), 7-29.

Brynjolfsson, E., A. Collis, W. E. Diewert, F. Eggers, and K. J. Fox (2019). GDP-B: Accounting for the value of new and free goods in the digital economy. Working Paper No. 25695 (March), National Bureau of Economic Research.

Brynjolfsson, E., A. Collis, and F. Eggers (2019). Using massive online choice experiments to measure changes in well-being. Proceedings of the National Academy of Sciences 116(15), 7250-7255.

Brynjolfsson, E. and A. Saunders (2009). Wired for innovation: How information technology is reshaping the economy. MIT Press.

Byrne, D. M. (2015). Prices for data storage equipment and the state of IT innovation. FEDS Notes (July 15), Federal Reserve Board, Washington, D.C.

Byrne, D. M. and C. A. Corrado (2015a). Prices for communications equipment: Rewriting the record. Finance and Economics Discussion Series 2015-069 (September), Board of Governors of the Federal Reserve System, Washington, D.C.

Byrne, D. M. and C. A. Corrado (2015b). Recent trends in communications equipment prices. FEDS Notes (September 29), Federal Reserve Board, Washington, D.C.

Byrne, D. M. and C. A. Corrado (2017a). ICT asset prices: Marshalling evidence into new measures. Finance and Economics Discussion Series 2017-016 (February), Board of Governors of the Federal Reserve System, Washington.

Byrne, D. M. and C. A. Corrado (2017b). ICT Services and their Prices: What do they tell us about Productivity and Technology? International Productivity Monitor (33), 150-181.

Byrne, D. M. and C. A. Corrado (2020). The Increasing Deflationary Influence of Consumer Digital Services, Technical report (forthcoming).

Christensen, L. R. and D. W. Jorgenson (1969). The measurement of US real capital input, 1929-1967. Review of Income and Wealth 15(4), 293-320.

Christensen, L. R. and D. W. Jorgenson (1973). Measuring economic performance in the private sector. In M. Moss (Ed.), The Measurement of Economic and Social Performance, pp. 233-351. NBER.

Copeland, A. (2013). Seasonality, consumer heterogeneity and price indexes: the case of prepackaged software. Journal of Productivity Analysis 39, 47-59.

Corrado, C. (2011). Communication capital, Metcalfe's law, and U.S. productivity growth. Economics Program Working Paper 11-01, The Conference Board, Inc., New York. Available at http://papers.ssrn.com/sol3/ papers.cfm?abstract_id=2117784.

Corrado, C. and K. Jäger (2014). Communication networks, ICT, and productivity growth in Europe. Economics Program Working Paper 14-04, The Conference Board, Inc., New York.

Corrado, C. and O. Ukhaneva (2016). Hedonic Prices for Fixed Broadband Services: Estimation across OECD Countries. Technical report, OECD/STI Working Paper. 
Corrado, C. and O. Ukhaneva (2019). Hedonic Price Measures for Fixed Broadband Services: Estimation across OECD Countries, Phase II. Technical report, OECD/DSTI/CDEP Report to CISP and MADE, revised.

Corrado, C. A. and B. van Ark (2016). The Internet and productivity. In J. M. Bauer and M. Latzer (Eds.), Handbook on the Economics of the Internet, pp. 120-145. Northamption, Mass.: Edward Elgar Publishing, Inc.

Díaz-Pinés, A. and A. G. Fanfalone (2015). The role of triple- and quadruple-play bundles: Hedonic price analysis and industry performance in France, the United Kingdom, and the United States. Paper presented at 43rd research conference on commmunications, information and internet policy, George Mason University School of Law, Arlington, VA.

Diewert, W. E. and K. Fox (2017). The digital economy, GDP and consumer welfare, paper presented at the CRIW workshop, NBER Summer Institute, Cambridge MA (July 17-18).

Gordon, R. J. (1990). The Measurement of Durable Goods Prices. Chicago: University of Chicago Press.

Greenwood, J. and K. A. Kopecky (2013). Measuring the welfare gain from personal computers. Economic Inquiry 51(1), 336-347.

Hulten, C. (1986). Productivity change, capacity utilization, and the sources of efficiency growth. Journal of Econometrics 33, 31-50.

Hulten, C. (2009). Growth accounting. Working paper, NBER Working Paper 15341 (September).

Hulten, C. R. and F. C. Wykoff (1981a). The estimation of economic depreciation using vintage asset prices. Journal of Econometrics 15, 367-396.

Hulten, C. R. and F. C. Wykoff (1981b). The measurement of economic depreciation. In C. R. Hulten (Ed.), Depreciation, Inflation 85 the Taxation of Income from Capital, pp. 81-125. The Urban Institute.

Jorgenson, D. W. (1963). Capital theory and investment behavior. American Economic Review 53(2), 247-259.

Jorgenson, D. W. and Z. Griliches (1967). The explanation of productivity change. The Review of Economic Studies 34(3), 249-283.

Jorgenson, D. W. and J. S. Landefeld (2006). Blueprint for expanded and integrated U.S. accounts: Review, assessment, and next steps. In D. W. Jorgenson, J. S. Landefeld, and W. D. Nordhaus (Eds.), A New Architecture for the U.S. National Accounts, Volume 66 of NBER Studies in Income and Wealth, pp. 13-112. Chicago: University of Chicago Press. Available at http://www.nber.org/chapters/c0133.pdf.

Nakamura, L., J. Samuels, and R. Soloveichik (2016). Valuing 'free' media in GDP: An experminental approach. Technical report, Bureau of Economic Analysis.

Nakamura, L., R. Soloveichik, and J. Samuels (2018). "Free" Internet Content: Web 1.0, Web 2.0, and the sources of economic growth. Technical Report Research Paper WP 18-17, Federal Reserve Bank of Philadelphia.

Petrin, A. (2002). Quantifying the benefits of new products: The case of the minivan. Journal of Political Economy 110(4), 705-729.

Rotemberg, J. J. and M. Woodford (1995). Dynamic general equilibrium models with imperfectly competitive product markets. In T. F. Cooley (Ed.), Frontiers of Business Cycle Research, pp. 243-293. Princeton University Press.

U.S. Department of Commerce. Bureau of Economic Analysis (2003). Fixed Assets and Consumer Durables Goods in the United States, 1925-99. Washington, D.C.: U.S. Government Printing Office.

Williams, B. (2008). A hedonic model for Internet access service in the Consumer Price Index. Monthly Labor Review (July), 33-48. 


\section{Appendixes}

\section{A1 Network utilization}

This appendix provides a derivation of equation 18 in the main text, i.e., we set out how to extract a measure of network capital utilization from productivity data and documents the calculations reported in section 3.1.

\section{A1.1 Derivation}

What follows is based on the framework set out for analyzing communication networks and network externalities in Corrado (2011), in which it is assumed there no markups due to imperfect competition or other inefficiency wedges; see also Corrado and Jäger (2014) and Corrado and van Ark (2016).

In sources-of-growth accounting, the contribution of private capital is expressed in terms of the services it provides. Let the value of the relevant private stocks be denoted as $P^{I} K$ where the price of each unit of capital $P^{I}$ is the investment price and the real stock $K$ is a quantity obtained via the standard perpetual inventory model. In our application, the value $P^{I} K$ represents the replacement value of network service provider capital in terms of its capacity to deliver digital services (i.e., including in this application, the value of the "originals" for the content the provider can diseminate). The value $P^{K} K$ represents the service flow provided by that capital.

The price $P^{K}$ is an unobserved rental equivalence price, but which is related to the investment price by the user cost formula, $P^{K}=P^{I}(r+\delta-\pi) T$, where $r$ is an after-tax ex post rate of return, $\delta$ the depreciation rate used in the perpetual inventory calculation, $\pi$ is capital gains, and $T$ is the Hall-Jorgenson tax term. The rental equivalence price is simplified by defining the gross return $\Phi=(r+\delta-\pi) T$, so that when capital services $P^{K} K$ are equated with observed capital income via the residual calculation of an ex post after-tax rate of return $r$, we have

$$
\text { observed capital income }=P^{I} K * \Phi
$$

When capital services are computed on the basis of an ex ante financial rate of return $\bar{r}$, the value for capital income of network providers must be expressed differently. Defining the ex ante gross return $\bar{\Phi}=(\bar{r}+\delta-\pi) T$ accordingly, network provider capital income is expressed as

$$
\text { observed capital income }=P^{I} K u^{I S P} * \bar{\Phi}
$$

where $u^{I S P}$ is network capital utilization and, via Berndt and Fuss (1986), capital utilization $u^{I S P}$ (rather than $r$ ) exhausts capital income.

Equating expressions A1 and A2

$$
P^{I} K * \Phi=P^{I} K u^{I S P} * \bar{\Phi}
$$

and solving for $u^{I S P}$ yields

$$
u^{I S P}=\frac{\Phi}{\bar{\Phi}}
$$

This equation states that under the conditions set out in Berndt and Fuss (1986) the relationship between the ex post and ex ante gross rate of return for an industry or sector reflects its capital utilization.

\section{A1.2 Calculations}

The implied network utilization calculating according to equation (A3) where $r$ in the definition of $\Phi$ is calculated following Jorgenson and Griliches (1967) as the ex post return for the combined Motion Picture, Sound Recording, Telecommunications, and Broadcasting industries (NAICS 512,515,517) and where $\bar{r}$ in the definition of $\bar{\Phi}$ is set to Moody's AAA corporate bond rate.

The ex post net return and the $\delta$ and $\pi$ components of $\Phi$ and $\bar{\Phi}$ were calculated by the authors for the combined sector using data from BEA's industry accounts (accessed October 2018). The results for $u$ are shown in text figure 6 . 


\section{A2 Access Service Prices and Consumption}

To calculate a price index for each of the network access services provided by the business sector - cable, internet, mobile, and subscriptionvideo streaming - we begin with nominal spending and divide by a measure of aggregate time spent using the service adjusted for quality. These individual price indexes are aggregated to create an overall access price index used to deflate nominal spending on access services and produce a measure of consumption.

For exposition and analysis, we also consider price indexes constructed using four alternative measures of quantity: the number of households subscribed to the service, the number of individual users, time spent on the service, and time spent adjusted for quality (our preferred measure for deflation). Thus four alternative indexes are calculated for each of the four services by dividing revenue by each of the alternative measures of quantity, yielding prices paid per household, per individual, per unit of time, and per unit of constant-quality time: $P_{H}$, $P_{I}, P_{D}$, and $P_{Q}$.

Data sources and calculation methods for service prices are summarized in table A-1.

\section{A2.1 Nominal Spending}

For nominal spending, we use figures from the national accounts published by Bureau of Economic Analysis, table 2.4.5U, "Personal Consumption Expenditures by Type of Product." In the cases of mobile access and video on demand, we developed additional detail as explained below.

Cable Spending is taken from table line 215, "Cable, satellite, and other live television services." We use "cable" as shorthand for spending in this category, which includes spending on the services of multi-channel video programming distributors (MVPDs) of all kinds, including in addition to cable television, programming provided via telecommunications service provider, direct broadcast satellite, home satellite dish, wireless cable, master antenna, and open video systems.

Internet Spending is taken from table line 285, "Internet access." Spending on internet services includes access via "dial-up" service and access via broadband whether obtained through a telecommunications service provider, a cable system, or a satellite system. We extrapolate a spending figure for 1987 using the growth rate of internet households.

Mobile Spending is taken from table line 281, "Cellular telephone services." Mobile services spending includes access to broadband via smartphone as well as access to conventional features such as voice and text using smartphone or feature phone. We split nominal access spending between smartphone service and feature phone service, for which we construct distinct quantity measures, using the number of subscribers of each type (derived as explained below) and a judgmental assumption that price paid for a smartphone contract is four times the price paid for a feature phone contract. (At the time of writing, a casual review of prices on the Worldwide Web showed basic plans with no data were $\$ 10-15$ per month and common smartphone plans were $\$ 40-60$ per month.)

Video Total video spending is taken from table line 220, "Video streaming and rental." 18 We focus on subscription video on demand (SVOD), which we use as an indicator for the broader category, due to data limitations ${ }^{19}$ In particular, we construct estimates of revenue for the three most prominent SVOD providersNetflix, Amazon Prime, and Hulu - based on company financial reports and press reports. Netflix reports revenue per subscription beginning in 2012, which we extrapolate back to 2007 using the modest 2012-2013 growth rate. Revenue per subscription for Amazon and Hulu are assumed to be their standard charges $(\$ 7.99$ per month for Hulu and $\$ 79$ per year for Amazon Prime through 2013 and $\$ 99$ per year afterward). These figures are multiplied by the number of households for each service estimated as described below.

\footnotetext{
${ }^{18} \mathrm{BEA}$ also provides revenue for "Audio streaming and radio services (including satellite radio)" . We did not develop a price index for this category.

${ }^{19}$ In addition to SVOD, video streaming and rental as defined in the NIPAs encompasses one-off video on demand, such as sports events, and rental of DVDs, for which we do not have data.
} 


\section{A2.2 Households}

Cable Periodic reports from the FCC, "Status of Competition in Markets for the Delivery of Video Programming," provide household subscription figures for 1990 to 2015, citing reports by consulting firm SNL Kagan. Earlier years were collected from Statistical Abstracts of the United States, which reports figures from Census of Housing. Figures for 2016 and 2017 were extrapolated using available reports from cable, telecom, and satellite service companies (Chartered, Comcast, AT\&T, Verizon, DIRECTV, and DISH).

Internet Periodic reports from the FCC, "Internet Access Services: Status," provide household figures for broadband access for 1999-2016 and dial-up access for 2001-2009. Prior to 1999, we assume all access was via dial-up service. Dial-up service figures for years not covered by FCC reports were available from financial reports and press reports for America Online, Compuserve, Prodigy, Microsoft Network, AT\&T Worldnet, and Genie. The company series were judgmentally extrapolated to the year of introduction for each service. Dial-up subscribers from 2010 onward were extrapolated using figures from America Online (AOL) through 2014 and the 2011-2014 rate of AOL subscription decline for 2015-2017.

Mobile We do not have data on the number of households with cell phone service. We assume the share of households with service equals the share of individuals in the adult population with service.

Video Netflix reports the number of paying members beginning in 2009, which we extrapolate back to 2007 using the 2009-2010 growth rate. Hulu and Amazon subscribers are collected from press reports, which typically cite estimates from eMarketer. Because eMarketer figures estimate the number of active users using an assumption of 2.5 users per subscribing household, we multiply these reported user figures by 0.4 to estimate the number of households, assuming one subscription per household.

\section{A2.3 Individuals}

Cable We scale cable household figures using the number of residents at least two years of age per TV household reported by Nielsen for 1985, 1990, 1995, 2000, 2005, and 2010, interpolated and extrapolated.

Internet In 1998, 2000, 2001, 2003, 2007, 2009-2013, 2015, and 2017, the Current Population Survey supplemental survey on computer and internet use provided estimates of the share of people living in a household with an internet connection and the share of individuals going online at home. We use this information to construct a time series for the share of people who use the internet at home for 1998-2017 for adults and children separately. We extrapolate these shares back to 1987 using the growth rate for 1998-2009. These shares are applied to the average composition by age of U.S. households to derive the total number of home internet users by year.

Mobile Number of cellphone users (smartphone and feature phone collectively) is taken from Consumer Telecommunications Industry Association (CTIA) estimates as reported in Statistical Abstracts of the United States for 1987-2004. Estimates for 2005-2017 are from population shares reported by the Pew Research Center (Pew) times the U.S. population. Pew also provides separate estimates for smartphone users, which are subtracted from total cellphone users to get (solely) feature phone users.

Video For each SVOD service, the number of users is estimated by multiplying the number of households times the average household size reported by the U.S. Census for the year. That is, we assume all household members make use of the service.

\section{A2.4 Time Use}

Cable The Nielsen Corporation (Nielsen) provides time spent per day on live and time-shifted television by age group (2-11 years old, 12-17 years old, at least 18 years old) beginning in 1992, which we extrapolate to 1987 using the value for 1992. We weight these figures by the U.S. Census-reported share of the population at least 2 years old for each age group to get an average hours per day for residents of households with cable access which we multiply by total users to get total hours. 
Internet Hours spent using the internet for 1992-2008 were used from Statistical Abstracts of the United States, various years, reporting estimates published by Veronis, Suhler, Stevenson (VSS). For 2011-2017, Nielsen reports of time spent accessing the internet on a computer were used. Estimates for 2009-2010 were interpolated and for 1987-1991 a growth rate of 50 percent per year was assumed, yielding a trivial level for 1987 in order to match a report from VSS that hours were negligible prior to 1987.

Mobile Our measure of time use for feature phones is talk time. Minutes of talking is calculated as a threeyear centered moving average of estimates taken from FCC reports, citing CTIA surveys for 1993-2014 and extrapolated. For smartphones, we use a three-year centered moving average of estimates from eMarketer available for 2011-2017 of average time spent per day with smartphones for U.S. adults, which we extrapolate back to 2005 .

Video To calculate hours spent on each SVOD service, we first estimate the data used in streaming using the share of internet traffic for each service reported by Sandvine, Inc. multiplied by the quantity of fixed internet traffic for the North American consumer market reported by Ciscos Visual Networking Index (VNI) reports. Sandvine reports are available annually from 2010 to 2014 and for 2016; the shares for 2014 are linearly interpolated and the share for each service for 2017 is set equal to its 2016 value. Then we divide by the number of bytes required to stream an hour of video to get the number of hours. The estimate of bytes per hour used is a weighted average of the number of bytes used for standard definition and high definition video streaming, where the share is estimated using VNI reports. In particular, VNI provides a high-definition share for SVOD of 0.59 for 2014. This estimate is extrapolated to 2010 using the growth reported in VNI for the high definition share of global managed IP video-on-demand traffic. The share is extrapolated further back to 2007 using a 5 percent growth rate, and forward to 2017 using the VNI forecast published in 2014, the last VNI vintage where Cisco provided data on the subject.

\section{A2.5 Quality-Adjusted Hours}

Cable To account for the increase in quality associated with the programming choices available to viewers, we scale hours by the average number of channels per cable system reported by the FCC. We use a natural $\log$ transformation, assuming for example that the additional quality obtained going from 100 to 200 channels equals the increase in quality obtained going from 10 to 20 channels.

Internet Our indicator for quality of internet service is the VNI estimate of IP traffic for consumer fixed internet use for North America. We use North American traffic in the absence of information on the U.S. share, essentially assuming that the U.S. share of North American traffic is unchanged over time. Direct measures of the indicator is available for 2005-2016, along with a forecast for 2017 from the latest VNI reports, various years. We extrapolate back to 1994 using overall fixed internet traffic estimates for North America, and back to 1990 using global fixed internet traffic from VNI reports. For 1987-1989 we use the 1990-1993 growth rate.

Mobile We assume the quality of talk time is unchanged over time, so no quality adjustment is necessary for feature phones. For smartphones, we use the volume (petabytes) of consumer mobile IP traffic per month for the North American market reported by VNI for 2005-2017, extrapolated to 2002 using the average growth rate for 2005-2008.

Video Our quality-adjusted series is raw hours of viewing time scaled by a library quality indicator and multiplied by high-definition video share. Our indicator for the quality of SVOD service is the natural log of the size of the video library for each service measured in the number of equivalent feature films available for streaming. FCC reports in 2013 and 2016 provide data on the number of films and the number of TV seasons available on each service. Estimates from the press were found for 2010 and 2018. Netflix press releases provide data for 2007 and 2008. Missing years are interpolated. We reweight TV seasons using the judgmental assumption that two episodes of a television show are equivalent to one feature film and TV seasons have 15 episodes. The high-definition share adjustment employed to calculate hours of viewing time above is reverse to produce the quality-adjusted hours indicator, implying that the quality of high-definition viewing is 1.67 times the quality of standard-definition viewing, corresponding to the ratio of data transmission required for each type, 5 megabits per second and 3 megabits per second, respectively. 


\section{A2.5.1 Price Indexes}

Table A-2 shows the quality-adjusted price index for each access service and price indexes for each concept of quantity. Our aggregate quality-adjusted price index for access service, shown in the right-most column, falls 12.4 percent per year, on average, over the full period of this study. The price index decline accelerates over time, first as internet service accounts for a rising share of spending, in the 1997-2007 period, then as mobile and video on demand access become more important in the 2007-2017 period. (Decomposition of growth in the final index into contributions from each margin is discussed in the paper.) 


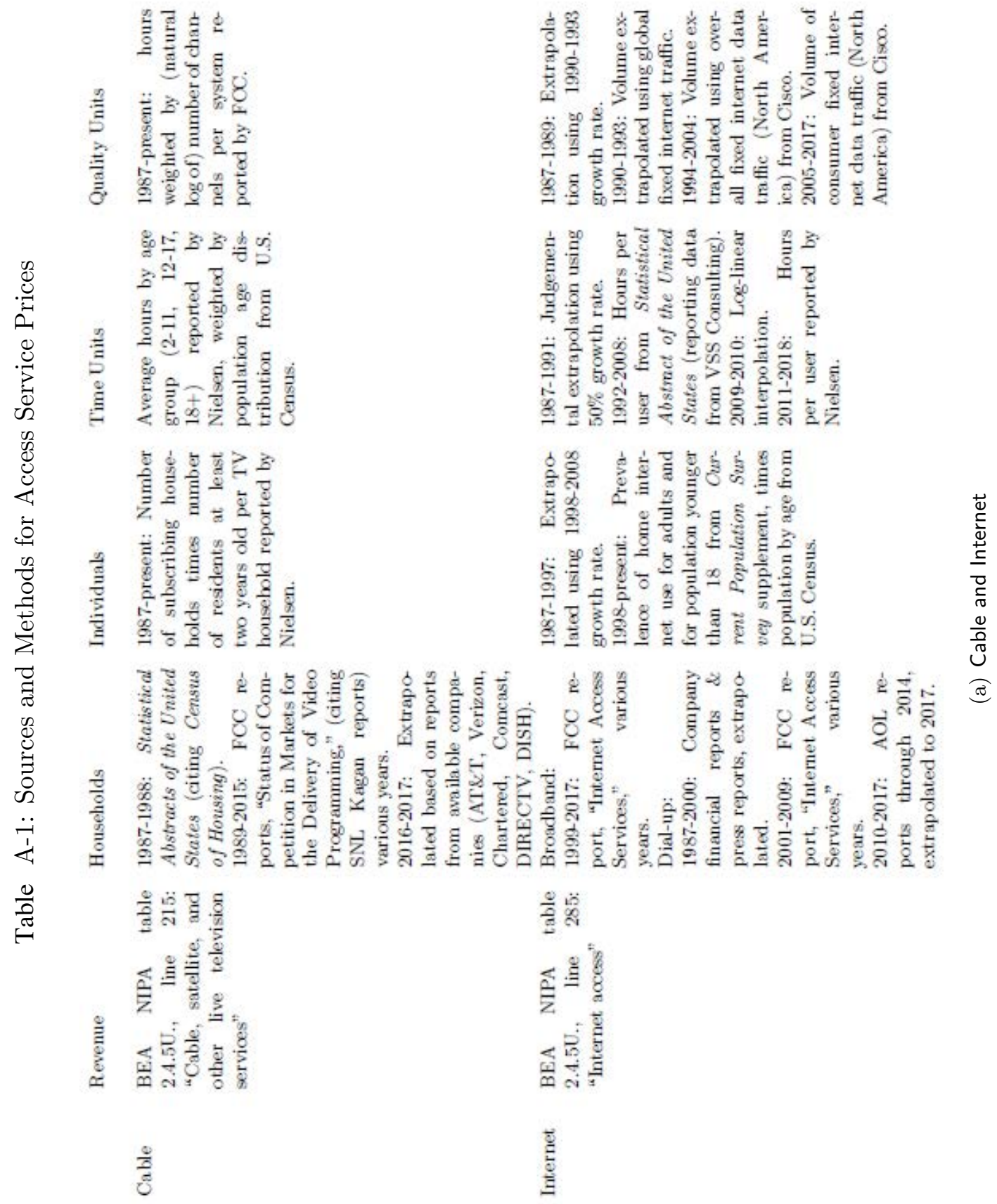



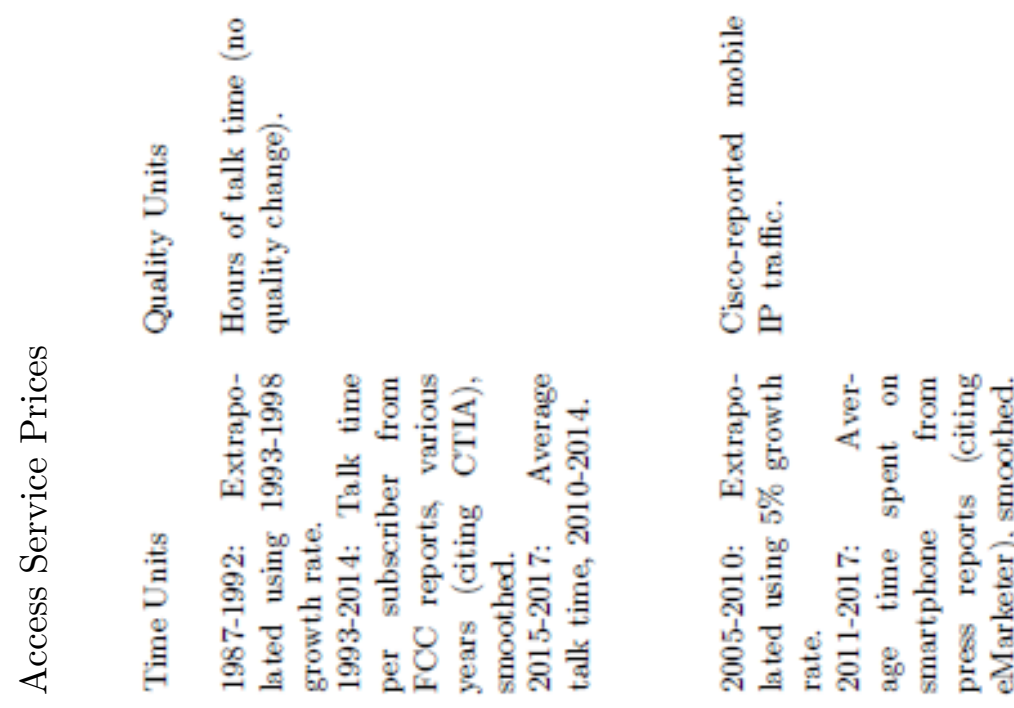

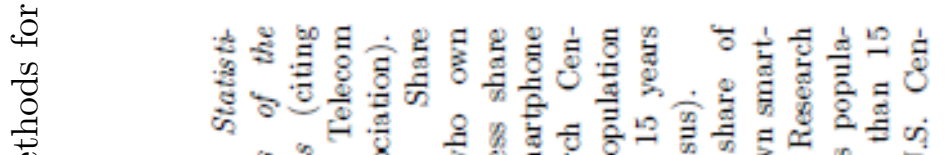

苞

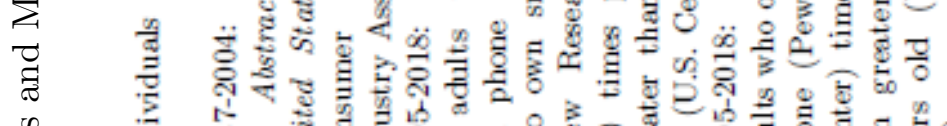

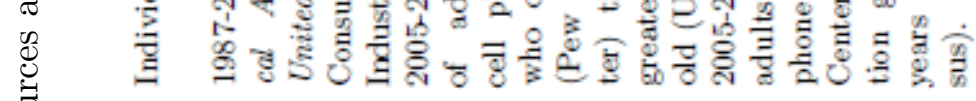

ชై

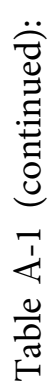

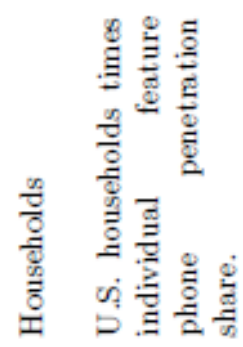

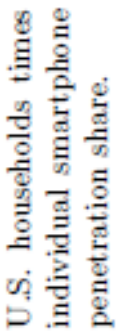

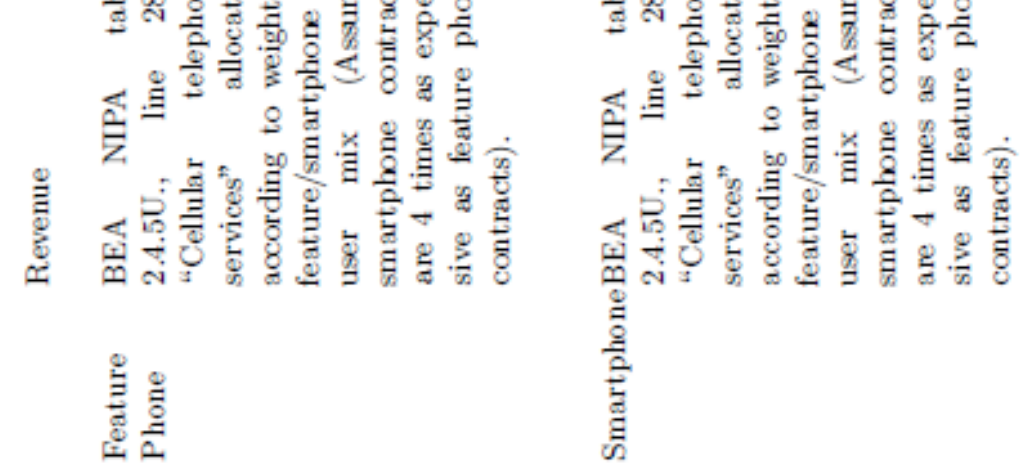




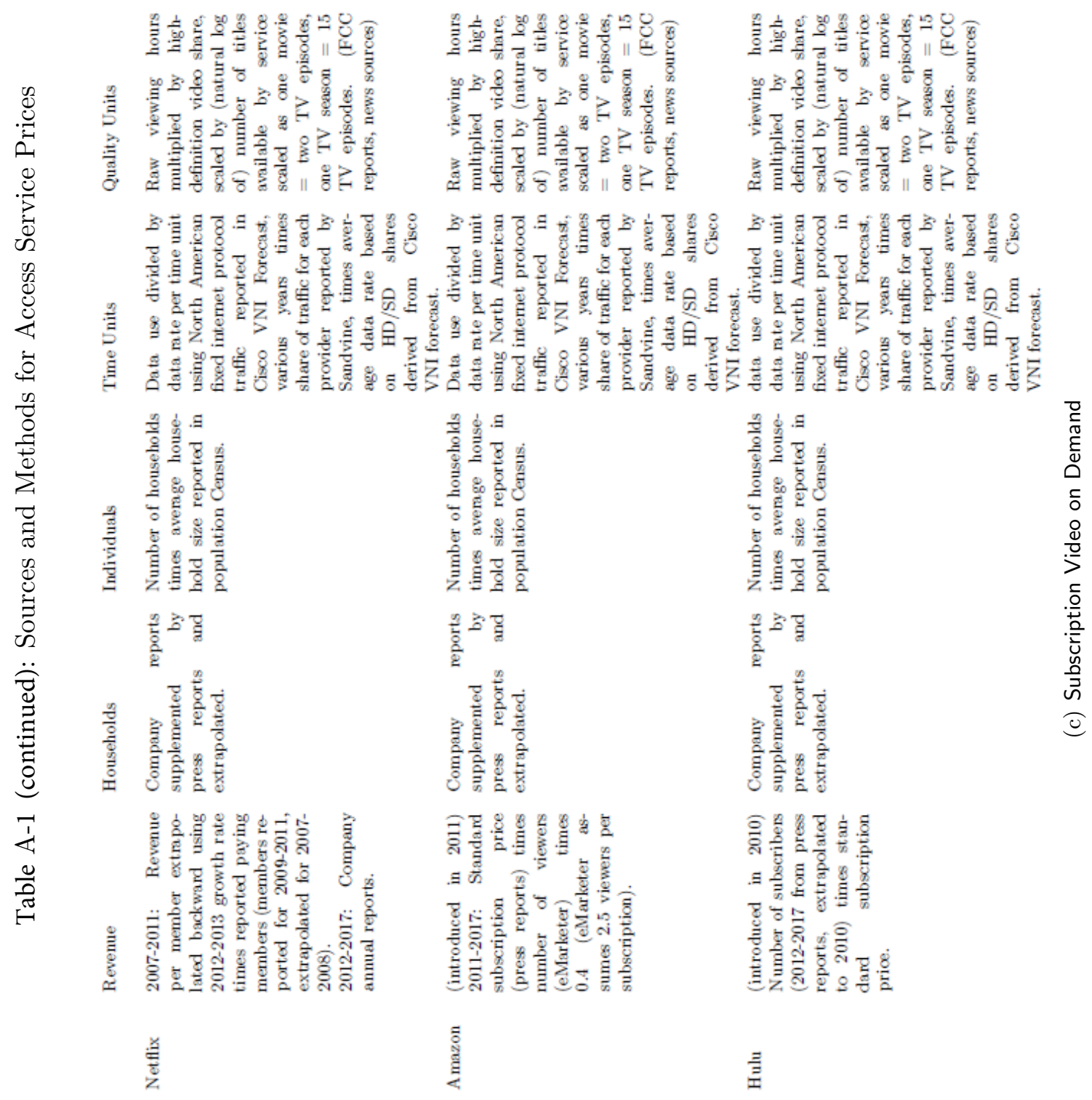


Table A-2: Price Indexes for Access Services

Quality-Adjusted Price Index by Service Aggregate Service Price for Alternative Units

\begin{tabular}{|c|c|c|c|c|c|c|c|c|}
\hline Year & Cable & Internet & Mobile & Video & Household & User & Hour & Quality \\
\hline 1987 & 62.40 & $2,158,866.63$ & $1,691.56$ & ND & 62.74 & 62.60 & 171.95 & 492.25 \\
\hline 1988 & 63.61 & $1,630,616.32$ & $2,076.07$ & ND & 64.29 & 64.49 & 177.27 & 504.31 \\
\hline 1989 & 72.05 & $1,590,688.49$ & $2,366.66$ & ND & 73.47 & 74.10 & 201.91 & 571.27 \\
\hline 1990 & 77.42 & $1,476,658.56$ & $2,206.42$ & ND & 79.68 & 80.72 & 215.08 & 605.28 \\
\hline 1991 & 77.17 & $1,476,658.56$ & $1,791.89$ & ND & 79.35 & 80.18 & 209.93 & 588.03 \\
\hline 1992 & 82.59 & $1,125,952.15$ & $1,634.17$ & ND & 84.69 & 85.44 & 219.88 & 611.09 \\
\hline 1993 & 83.96 & $608,383.33$ & $1,256.09$ & ND & 84.48 & 85.00 & 211.99 & 582.35 \\
\hline 1994 & 77.40 & $594,355.07$ & 934.09 & ND & 77.39 & 77.53 & 187.02 & 509.98 \\
\hline 1995 & 77.75 & $116,043.76$ & 745.84 & ND & 78.01 & 77.81 & 178.29 & 439.39 \\
\hline 1996 & 83.07 & $18,465.35$ & 725.84 & ND & 79.33 & 79.38 & 181.38 & 386.76 \\
\hline 1997 & 92.62 & $8,883.37$ & 664.56 & ND & 81.19 & 81.07 & 183.51 & 381.03 \\
\hline 1998 & 98.15 & $5,389.04$ & 628.31 & ND & 84.62 & 84.55 & 183.93 & 371.65 \\
\hline 1999 & 103.06 & $3,869.68$ & 542.59 & ND & 88.44 & 88.49 & 183.37 & 351.24 \\
\hline 2000 & 108.05 & $1,973.82$ & 436.65 & ND & 94.71 & 94.87 & 177.46 & 304.20 \\
\hline 2001 & 105.71 & 880.03 & 327.16 & ND & 99.63 & 100.01 & 154.95 & 240.57 \\
\hline 2002 & 104.80 & 491.32 & 277.21 & ND & 101.17 & 102.73 & 145.78 & 206.70 \\
\hline 2003 & 102.06 & 311.61 & 221.78 & ND & 102.36 & 103.98 & 134.44 & 173.59 \\
\hline 2004 & 106.52 & 185.71 & 187.51 & ND & 103.01 & 104.72 & 128.90 & 151.64 \\
\hline 2005 & 103.10 & 115.31 & 155.39 & ND & 102.73 & 103.39 & 116.75 & 128.21 \\
\hline 2006 & 99.13 & 114.93 & 127.98 & ND & 102.20 & 102.59 & 108.33 & 114.85 \\
\hline 2007 & 100.00 & 100.00 & 100.00 & 100.00 & 100.00 & 100.00 & 100.00 & 100.00 \\
\hline 2008 & 103.51 & 81.92 & 78.07 & 62.65 & 99.44 & 99.45 & 94.48 & 86.94 \\
\hline 2009 & 104.86 & 51.17 & 51.43 & 47.85 & 95.47 & 95.35 & 84.74 & 66.34 \\
\hline 2010 & 107.61 & 36.55 & 32.69 & 36.60 & 98.17 & 97.45 & 81.33 & 51.36 \\
\hline 2011 & 105.70 & 27.51 & 20.91 & 17.93 & 94.99 & 94.89 & 73.15 & 39.44 \\
\hline 2012 & 112.03 & 26.50 & 14.51 & 14.81 & 92.85 & 91.48 & 66.96 & 33.99 \\
\hline 2013 & 113.01 & 24.77 & 7.25 & 13.20 & 90.13 & 89.76 & 60.96 & 24.97 \\
\hline 2014 & 120.32 & 23.46 & 4.43 & 12.68 & 94.85 & 94.26 & 63.92 & 20.45 \\
\hline 2015 & 145.81 & 16.03 & 2.85 & 9.00 & 93.70 & 92.50 & 64.61 & 16.63 \\
\hline 2016 & 150.56 & 11.47 & 2.14 & 6.59 & 96.56 & 95.31 & 68.10 & 13.75 \\
\hline 2017 & 161.95 & 9.65 & 1.61 & 6.56 & 98.01 & 96.93 & 70.10 & 12.05 \\
\hline \multicolumn{9}{|l|}{ Growth rate } \\
\hline $1987-2017$ & $3.2 \%$ & $-41.1 \%$ & $-23.2 \%$ & ND & $1.5 \%$ & $1.5 \%$ & $-3.0 \%$ & $-12.4 \%$ \\
\hline $1987-1997$ & $3.9 \%$ & $-54.9 \%$ & $-9.3 \%$ & ND & $2.6 \%$ & $2.6 \%$ & $0.7 \%$ & $-2.6 \%$ \\
\hline $1997-2007$ & $0.8 \%$ & $-44.9 \%$ & $-18.9 \%$ & ND & $2.1 \%$ & $2.1 \%$ & $-6.1 \%$ & $-13.4 \%$ \\
\hline $2007-2017$ & $4.8 \%$ & $-23.4 \%$ & $-41.3 \%$ & $-27.2 \%$ & $-0.2 \%$ & $-0.3 \%$ & $-3.6 \%$ & $-21.2 \%$ \\
\hline
\end{tabular}




\section{A3 Consumer IT Durable Prices and (Household) Investment}

Data Sources and methods used for constructing nominal consumer durable spending and price indexes used for deflation are summarized in table A-3.

\section{A3.1 Nominal Spending}

Nominal spending estimates were based on detailed personal consumption expenditures reported by BEA In particular, detailed annual-frequency estimates of spending by product type were allocated to the more detailed categories used in the paper based on the 2007 input-output tables. (The quinquennial "benchmark" inputoutput table from 2007 provides not only detailed product spending information but also commodity codes corresponding to the primary products of the industries of the North American Industry Classification System (NAICS).) For example, the annual-frequency estimates of PCE detailed spending include a category for "video, audio, photographic, and information processing equipment" with further detail provided for 8 commodity codes, including "computer and electronic products." The 2007 input-output table provides for the 6-digit industry of origin of the products within this category, allowing one to distinguish among personal computers, computer monitors, televisions, and so forth.

In the case of cellular phones and digital cameras, outside sources were used. Although these categories can be derived using the method described, their share of expenditure has changed rapidly since 2007, rendering the allocation process inaccurate. Expenditures on other products which share the relevant higher-level categories are offset proportionally to accomodate the rising spending on cell phones and the rise and subsequent rapid fall in spending on digital cameras.

Cell phones We use an estimate of cellular phone spending in the U.S. consumer market provided by IDC, Inc., rather than estimates reported in the NIPA PCE detail tables for several reasons. Cellular phone equipment spending is not reported separately, appearing instead as part of a broader category, "telephone and related communication equipment". And, as noted in Aizcorbe, Byrne, and Sichel (2019), this broader NIPA spending line does not account for the substantial portion of the relevant acquisition of consumer stocks of cell phones which takes place in conjunction with the purchase of cellular phone services. In contrast, the estimates for IDC impute a value for cell phones acquired as part of a service contract using the price a consumer would pay for the phone if acquired without a contract commitment. The IDC estimates thus provide a consistent estimate of the retail value of all phones acquired over time, which serves the purpose of measuring the household capital stock. As shown in figure A-1, the IDC estimate of consumer cell phone expenditures is substantially higher than the NIPA estimate for the category containing cell phones. To corroborate the IDC estimate, we constructed an alternative estimate using U.S. sales at wholesale prices, provided by Gartner through 2007, extrapolated by cell phone imports which dominate the U.S. market reported by ITC, and inflated by 50 percent, a rough estimate of the retail margin in the cell phone market. This coarse indicator, shown by the gray line, is quite close to the IDC estimate.

Digital Cameras Unit sales of digital cameras for the Americas market provided by the Camera and Digital Products Association are scaled by an average price series constructed by interpolating between estimates reported in the press (falling from roughly $\$ 4,000$ in 1987 to roughly $\$ 200$ in 2007 and remaining stable since then). A U.S. share of total Americas spending is constructed using the relevant line from the benchmark input-output tables for 2007 for consumer spending on digital cameras, which yields a share of approximately 48 percent, which we assume is constant in our period of study.

\section{A3.2 Price Indexes}

For equipment prices, we use either official estimates or substitutes drawn from the authors' research and in some cases other national statistical agencies. Aggregate prices for three broad categories are shown in table A-4: audio-visual equipment (televisions, digital cameras, photographic equipment excluding digital cameras, other video equipment, audio equipment, and recording media), information processing equipment (personal computers, data storage equipment, monitors, and peripherals), and communications equipment (cellular phones and telephone equipment excluding cellular phones). 
Figure A-1: Estimates of U.S. Consumer Cell Phone Spending

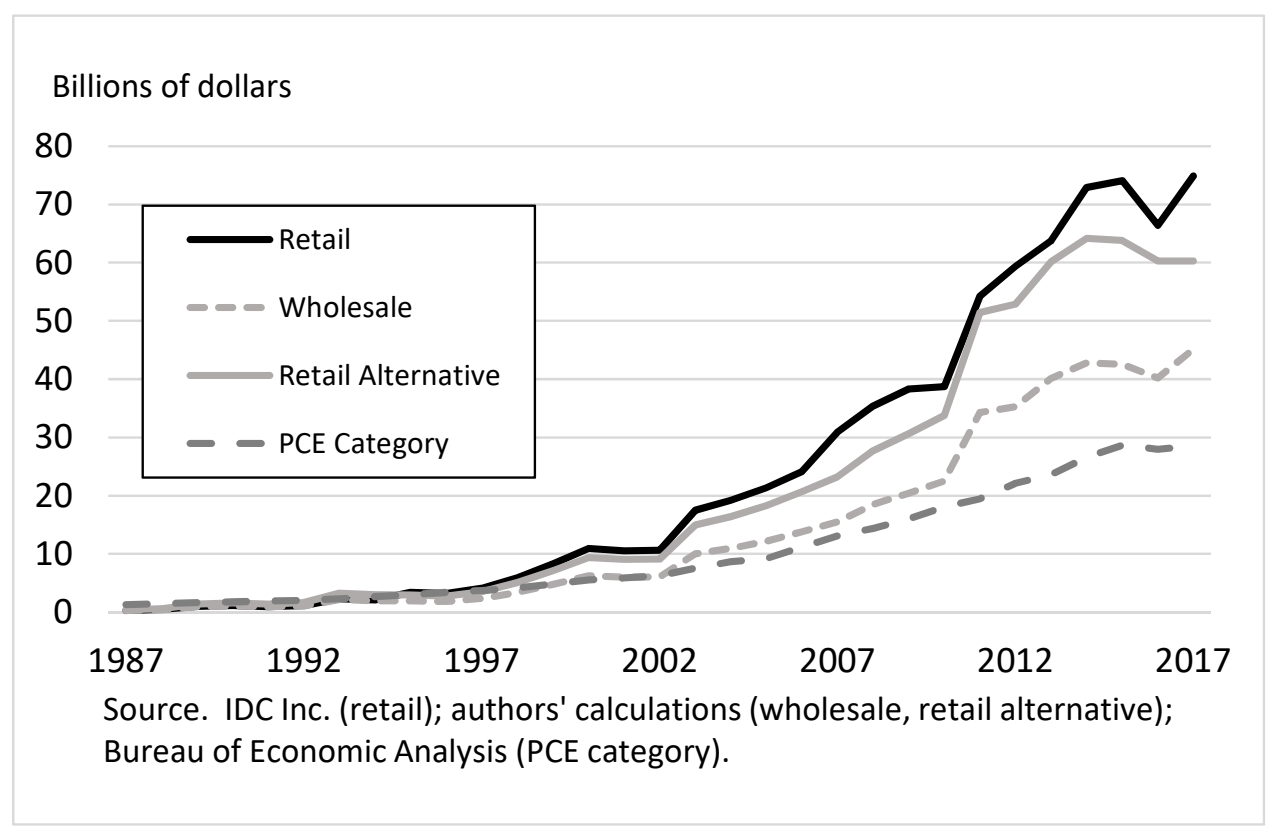

Televisions We use the BEA PCE deflator for televisions, which corresponds to the BLS CPI for televisions.

Digital cameras We use the CPI for cameras from Statistics Japan.

Photographic equipment excluding digital cameras We use the BEA PCE deflator for photographic equipment, which corresponds to the BLS CPI for photographic equipment.

Other video equipment We use the CPI for video cameras from Statistics Japan, available from 1990 forward, extrapolated backward using the Japanese CPI for cameras.

Audio equipment We use the BEA PCE deflator for audio equipment, which corresponds to the BLS CPI for audio equipment.

Recording media We use the BEA PCE deflator for recording media, which corresponds to the BLS CPI for video discs and other media.

Personal Computers We use the price index from Byrne and Corrado (2017a) for personal computers through 2014, extrapolated by the BEA PCE price for computers and peripherals augmented by the average difference between the growth rate of the BEA price index and the growth rate of the Byrne-Corrado price index for the 2009-2014 period.

Data storage equipment We use the price index published by the Federal Reserve Board for computer storage equipment, which extends the price index developed in Byrne (2015).

Monitors We use the BEA PCE deflator for televisions, which corresponds to the BLS CPI for televisions. 
Computer peripherals We use the price index from Byrne and Corrado (2017a) for peripherals through 2014, extrapolated by the BEA PCE price for computers and peripherals augmented by the average difference between the growth rate of the BEA price index and the growth rate of the Byrne-Corrado price index for the 2009-2014 period.

Other information processing equipment We use the BEA PCE deflator for calculators, typewriters, and other information processing equipment.

Software and accessories We use the price index for prepackaged software from Byrne and Corrado (2017a) for non-game PCE software, extrapolated for 2015-2017 using the 5-year average growth rate. For gaming PCE software, we use the BLS producer price index for game software publishing, available for 1998-2009 and 20142017, adjusted for the average difference between the PPI and Copeland (2013) over the 1998-2004 period. The 2010-2013 period is interpolated using the average growth rate in our index for the 2005-2009 period. For the 1987-1997 period, we use the BEA PCE price index for computer software and accessories.

Cell phones We use the Byrne and Corrado (2015a) price index for cell phones for the 1987-2010 period and the Aizcorbe et al. (2019) index for 2010-2017.

Telephone equipment excluding cellular phones We use the Byrne and Corrado (2017a) price index for telephones for the 1987-2014 period as extended and published by the Federal Reserve Board through 2017. 


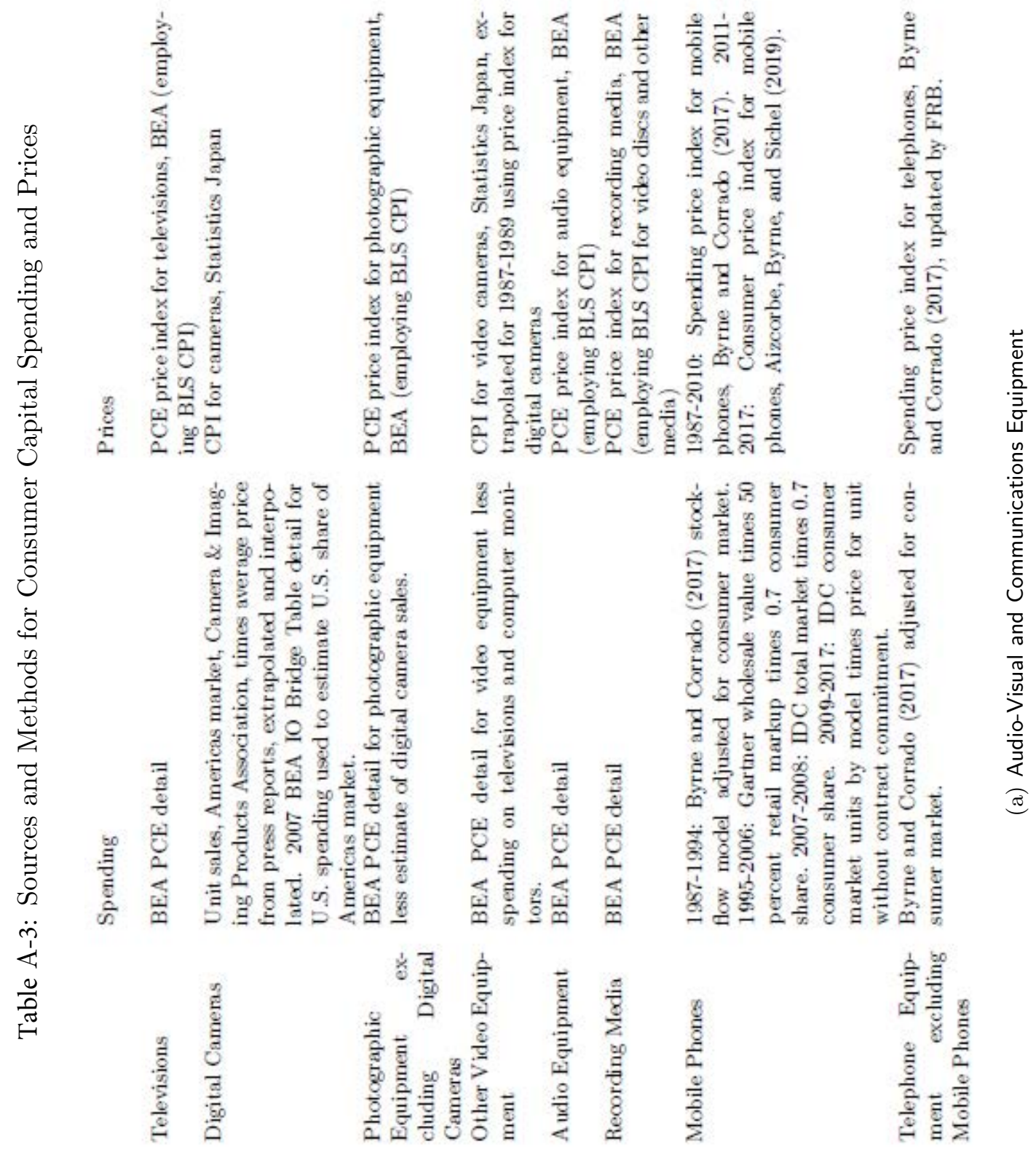




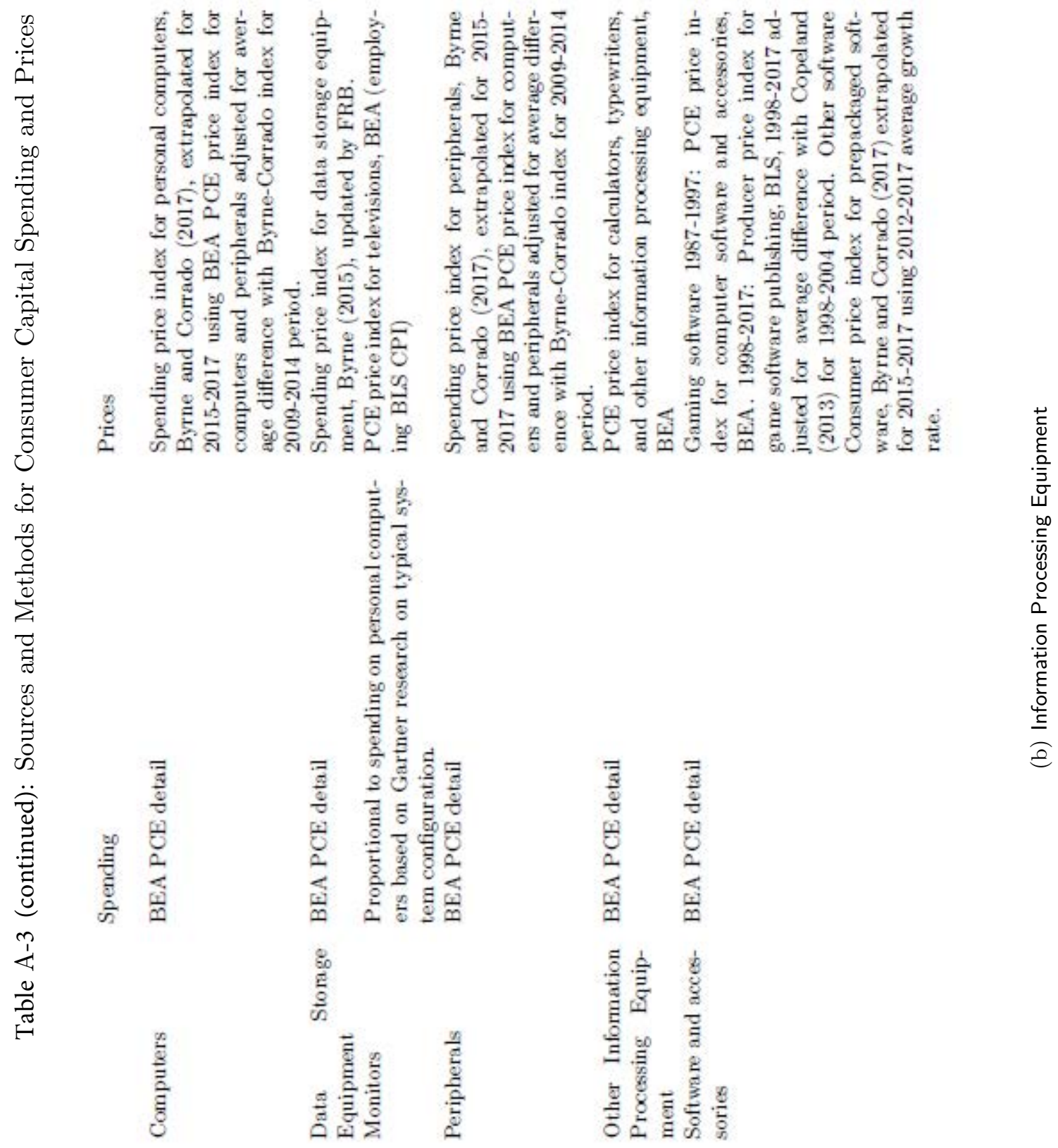


Table A-4: Price Indexes for ICT Durable Equipment Categories

Audio-Visual Info. Processing Communication

Equipment Equipment Equipment

\begin{tabular}{|c|c|c|c|}
\hline 1987 & 100.00 & 100.00 & 100.00 \\
\hline 1988 & 94.22 & 82.49 & 89.59 \\
\hline 1989 & 89.16 & 70.55 & 79.71 \\
\hline 1990 & 85.96 & 62.40 & 69.95 \\
\hline 1991 & 84.09 & 49.99 & 53.31 \\
\hline 1992 & 82.26 & 37.52 & 45.58 \\
\hline 1993 & 79.57 & 27.80 & 38.36 \\
\hline 1994 & 76.29 & 22.48 & 31.04 \\
\hline 1995 & 71.91 & 17.07 & 28.61 \\
\hline 1996 & 67.83 & 12.52 & 23.10 \\
\hline 1997 & 64.14 & 8.62 & 19.07 \\
\hline 1998 & 61.25 & 6.04 & 15.26 \\
\hline 1999 & 58.38 & 4.08 & 11.83 \\
\hline 2000 & 55.54 & 3.40 & 10.51 \\
\hline 2001 & 52.69 & 2.91 & 8.00 \\
\hline 2002 & 48.43 & 2.53 & 6.43 \\
\hline 2003 & 44.48 & 2.12 & 5.30 \\
\hline 2004 & 40.84 & 1.80 & 4.57 \\
\hline 2005 & 36.71 & 1.42 & 3.97 \\
\hline 2006 & 32.29 & 1.06 & 3.37 \\
\hline 2007 & 27.34 & 0.82 & 2.92 \\
\hline 2008 & 23.88 & 0.62 & 2.51 \\
\hline 2009 & 19.66 & 0.48 & 2.16 \\
\hline 2010 & 16.26 & 0.41 & 1.85 \\
\hline 2011 & 13.96 & 0.34 & 1.68 \\
\hline 2012 & 12.03 & 0.30 & 1.45 \\
\hline 2013 & 10.54 & 0.25 & 1.25 \\
\hline 2014 & 9.20 & 0.22 & 0.95 \\
\hline 2015 & 8.25 & 0.19 & 0.78 \\
\hline 2016 & 7.36 & 0.16 & 0.63 \\
\hline 2017 & 6.72 & 0.14 & 0.54 \\
\hline
\end{tabular}

$\begin{array}{rrrr}\text { Growth rate } & & & \\ 1987-2017 & -9.0 \% & -21.8 \% & -17.4 \% \\ 1987-1997 & -4.4 \% & -24.5 \% & -16.6 \% \\ 1997-2007 & -8.5 \% & -23.6 \% & -18.8 \% \\ 2007-2017 & -14.0 \% & -17.4 \% & -16.9 \%\end{array}$




\section{A4 IT Equipment Use Intensity}

We construct measures of use intensity for each type of capital employed to connect to the access services discussed in the paper. These include personal computers and related capital (monitors, software, and data storage equipment), televisions, and cell phones. These use intensity measures allow us to identify the effect on IT capital services from users spending a greater share of their time on digital access services and consequently the imprint that free and purchased services have on consumption.

Mechanically, constructing use intensity for a particular type of capital requires allocating time spent on accessing each digital service to the capital used for the access. For example, use intensity for personal computers is proportional to the share of household time spent accessing fixed internet services plus the portion of time spent using SVOD when viewing programming through the computer. Likewise, television use intensity is affected by cable access and by a portion of SVOD viewing time as well. Using the ratio of aggregate time spent on each access service to the number of each type of capital held by households, we construct intensity measures as the share of the working day a given PC, TV, or cell phone is in use.

The sources for the elements in our calculation of $\psi$ are as follows.

Service adoption The adoption of access services by household is derived from the household figures cal-culated in the previous section and was shown in figure 7a. Subscription video on demand penetration has also risen briskly since appearing in 2007. The share of households with at least one of the major services reached 60 percent in 2017. Time spent on each service is allocated by device as discussed below.

Computers Estimates of households with a personal computer are provided by U.S. Census Bureau for 1984, 1989, 1993, and roughly annually from 1989 forward in collaboration with the supplemental survey published by Current Population Survey. The number of PCs per household is based on periodic reports from the Residential Electricity Consumption Survey published by the Energy Information Agency. As was shown by the black line in figure $7 \mathrm{~b}$, internet access among computer households was roughly 20 percent as of 1990 and was over 90 percent by 2007. The number of PCs per computer-holding households rose nearly doubled (figure 7c). Dividing the total number of hours on the computer by the number of devices, we find that the share of the working day the average $\mathrm{PC}$ was in use for accessing the internet or SVOD rose from 18 percent in 1987 to roughly 29 percent in 2017 (figure $7 \mathrm{~d})$. 20

Televisions Estimates of households with a television are provided by Statistical Abstracts of the United States, citing figures from Census of Housing. As was shown by the grey solid lines in figure 7, nearly all households had a television at the beginning of our period of study and this share remained above 90 percent as of 2017. The number of televisions per household is based on periodic reports from the Residential Electricity Consumption Survey published by the Energy Information Agency. Televisions per TV-using household moved up from roughly 2 to roughly $2-1 / 2$ by 2005 and has eased down a touch since then. Dividing the total number of hours by the number of TVs in use yields a share of the day that peaked in 2013 at roughly a third and has moved down noticeably since then. The use intensity of PCs and TVs was roughly equal in 2017.

Cell phones Mobile phones (whether feature phones or smartphones) are assumed to be present whenever individuals have service, so the issue of adoption of the service conditional on the presence of the equipment, does not arise. However, figure 7 showed that mobile phone adoption rose rapidly from 2007 to 2015 and advanced more slowly since then; cell phone adoption overall has stabilized at 90 percent. As noted above, we use individual adoption rates as proxies for the household adoption rate in the case of cell phones. The share of households with mobile phone service rose rapidly from essentially zero at the beginning of our period of study to over 90 percent as of 2013 and was stable through 2017. The number of hours of use shot up with the advent of widespread smartphone use, and the share of the working day phones are in use shot up as well and stood at 18 percent as of 2018.

\footnotetext{
${ }^{20}$ Note that time spent using of the computer for other purposes, which averaged about 2-1/2 hours per day, is not included in this figure.
} 